\title{
Characterization of Nanocrystalline-Nanoporous Nickel Oxide Thin Films Prepared by Reactive Advanced Gas Deposition
}

\author{
U. Cindemir, Z. Topalian, C. G. Granqvist, L. Österlund and G. A. Niklasson* \\ Department of Engineering Sciences, The Ångström Laboratory, Uppsala University, \\ P.O. Box 534, SE-751 21 Uppsala, Sweden
}

\begin{abstract}
Nanocrystalline-nanoporous $\mathrm{Ni}$ oxide is of much interest for gas sensors and other applications. Reactive advanced gas deposition (AGD) stands out as a particularly promising technique for making thin films of this material owing to the technique's separation between the growth of individual nanoparticles and their subsequent deposition to create a consolidated material on a substrate. Here we report on the characterization of Ni oxide films, made by reactive AGD, by several methods. X-ray diffractometry showed that the films had a face centered cubic $\mathrm{NiO}$ structure, and scanning electron microscopy indicated a nanoparticulate composition. X-ray photoelectron spectroscopy showed the presence of $\mathrm{Ni}^{3+}$ and demonstrated that these states became less prominent upon heat treatment in air. Extended x-ray absorption fine structure analysis elucidated the local atomic structure; in particular, data on interatomic distances and effects of annealing on local disorder showed that the Ni oxide nanoparticles crystallize upon annealing while maintaining their nanoparticle morphology, which is a crucial feature for reproducible fabrication of Ni oxide thin films for gas sensors. Importantly, several techniques demonstrated that grain growth remained modest for annealing temperatures as high as $400{ }^{\circ} \mathrm{C}$ for 1700 -nm-thick films. The present article is a sequel to an earlier one [U. Cindemir et al., Sensors and Actuators B 242 (2017) 132-139] in which we reported on fluctuation-enhanced and conductometric gas sensing with $\mathrm{Ni}$ oxide films prepared by AGD.
\end{abstract}

Keywords: nickel oxide; advanced gas deposition; EXAFS; atomic structure; gas sensor

* Corresponding author. E-mail: gunnar.niklasson@angstrom.uu.se 


\section{Introduction}

Materials combining nanocrystallinity and nanoporosity can exhibit interesting physical and chemical properties as a result of their large surface-to-volume ratios and the possible existence of regions with high surface energies and of phase compositions different from those in the bulk. Among these nanomaterials, thin films based on nickel oxide (NiO) have gained much attention for applications in gas sensors [1-29] as well as in other areas such as electrochromic devices [30-36] and catalysts of various types [37,38]. The sensed gases include acetone [5], ammonia [15,16,20], ethanol [5,7-9,26,27], formaldehyde $[2,4,12,13,17,23,28]$, hydrogen [11,18,19], hydrogen sulfide [3,6,14,21,25], methanol [5], nitrogen dioxide [1,3,6,10,22,29], toluene [5], trimethylamine [5], and xylene [24].

Conductometric gas sensors change their electrical properties upon exposure to gases that induce surface-chemical reactions with ensuing electron transfer at the interfaces between neighboring particulates in the sensor material [39-43], and it is obvious that the technique for making this material of is of central importance for its performance. Concerning NiO-based gas sensors, materials fabrication techniques have included physical deposition using sputtering $[1,2,4,15,25]$ and reactive gas deposition $[3,12,13]$, chemical preparation using various solution-based techniques [5,6,8,9,14,16,19-23,27-29], combustion-based methods [17], electrospinning [24], nanotemplating [26], spray coating [7], and sol-gel technology $[10,11,18,23]$.

Most methods for making nanocrystalline-nanoporous materials for gas sensors and other applications yield films whose structures are inextricably dependent on the deposition process, as has been investigated in detail especially for physical vapor deposition [44-47]. An exception, however, is gas deposition [48-51] which is noteworthy for its separation between the fabrication of individual nanoparticles and their subsequent deposition to create a consolidated material on a substrate and thus allows control of inter-particle contacts and thereby of the performance of a conductometric sensor. Gas deposition can be applied to make well-controlled nanomaterials and is industrially viable [52,53]; the technique is then usually referred to as advanced gas deposition (AGD) and is discussed in some detail below. AGD has been used to make gas sensors based on nanoparticles of $\mathrm{WO}_{3}$ [54-60], Auactivated $\mathrm{WO}_{3}$ [61], Pd-activated $\mathrm{WO}_{3}$ [62], organically surface-functionalized $\mathrm{Au}[63,64]$ and, as already noted, $\mathrm{NiO}[3,12,13]$. AGD-prepared $\mathrm{NiO}$ samples yielded the first highsensitivity detection of hydrogen sulfide and the first proof that such sensing can be 
accomplished at room temperature [3], which clearly attests to advantages of the sample preparation technique used in the present work.

Clearly $\mathrm{NiO}$ - which is a $p$-type semiconducting material with a face-centered cubic structure and a band gap of 3.6-4.0 eV [65] - has interesting properties for conductometric and noise-based gas sensing and other applications since the majority charge carriers (holes) do not interact with oxygen in air as in the case of $n$-type semiconductors, notably $\mathrm{SnO}_{2}$-based sensors. Details of the nanostructure-property relationship for $\mathrm{NiO}$ have remained poorly understood and, for example, as-deposited $\mathrm{Ni}$ oxide films prepared by AGD have yielded higher conductometric sensitivity upon ethanol exposure for an intermediate film thickness of $500 \mathrm{~nm}$ than when the thickness was 200 or $1700 \mathrm{~nm}$ [13]. The present paper reports results from a comprehensive analysis of the nano-features of AGD-produced $\mathrm{NiO}$ by use of several analytic techniques. The samples were subjected to annealing post-treatment in order to mimic typical fabrication processes for gas sensors. Our data are of interest for the development of NiO-based devices such as gas sensors, electrochromic devices, and catalysts. Results for gas sensing of formaldehyde, ethanol and methane gases by AGD-NiO films were presented in a recent paper of ours [13].

\section{Experimental techniques and procedures}

\subsection{Sample preparation}

Fig. 1 is a schematic presentation of the AGD setup, which comprises two stainless steel chambers connected by pipes. The lower (evaporation) chamber, where nanoparticles are produced, contains a gas whereas the upper (deposition) chamber, where a particulate film is formed on a substrate, is evacuated via a powerful vacuum pump. The pressure difference between the two chambers forces nanoparticles to flow via a transfer pipe from the evaporation chamber into the deposition chamber, and a nozzle at the upper part of the transfer pipe determines the pressure gradient between the two chambers. 


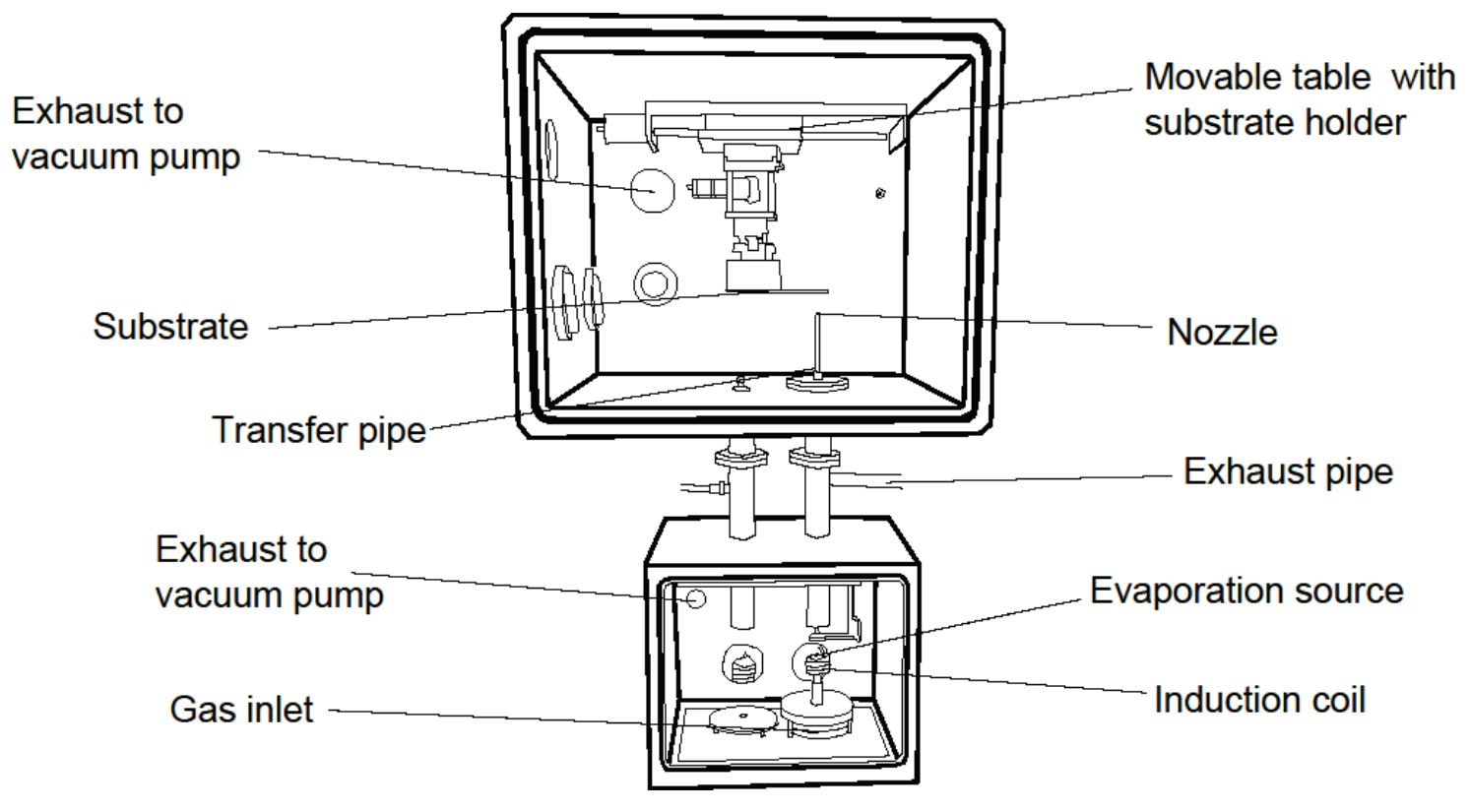

Figure 1. Schematic drawing of the advanced gas deposition system, illustrating its most essential components.

Nanocrystalline-nanoporous $\mathrm{NiO}$ thin-film samples were prepared by heating Ni pellets (purity 99.95\%), placed in a carbon crucible, via an RF coil. The evaporated species were oxidized in a laminar gas flow comprising 0.1 1/min of oxygen (purity 99.998\%) and 20 1/min of helium (purity 99.997\%). The oxidized Ni nanoparticles thus formed were transported through the transfer pipe into the deposition chamber, where $\mathrm{NiO}$ deposits where formed on substrates attached to a programmable $\mathrm{X}-\mathrm{Y}$-moving platform. Helium was chosen as carrier gas since it is known to yield especially small particles [50]. The samples to be discussed below were prepared with an evaporation pressure of 50-100 mbar, a deposition pressure of 0.3-0.6 mbar, a heating power of $3 \mathrm{~kW}$, and a nozzle diameter of $1 \mathrm{~mm}$. Samples designated 1, 2 and 3 had thicknesses equal to 1700, 600 and $300 \mathrm{~nm}$, respectively, and were deposited onto glass plates. The as-prepared $\mathrm{NiO}$ samples were subsequently annealed for $12 \mathrm{~h}$ at 300 , 400 and $500{ }^{\circ} \mathrm{C}$ in ambient air. The temperature was ramped up/down at 2.3/0.38, 3.1/0.52 and $4.0 / 0.66^{\circ} \mathrm{C} / \mathrm{min}$ for heat treatment at 300,400 and $500{ }^{\circ} \mathrm{C}$, respectively.

\subsection{Materials characterization techniques}

Film thickness measurements were performed by use of a Veeco Dektak 150 surface profilometer. Grazing incidence x-ray diffractometry (XRD) was carried out with a Siemens D5000 instrument using $\mathrm{Cu} \mathrm{K}$ radiation $\left(\lambda=1.5418 \AA\right.$ ); the incident beam angle was $1^{\circ}$, and 
diffraction angles $2 \theta$ were in the $20-90^{\circ}$ range. Scanning electron microscopy (SEM) images were recorded using a Zeiss LEO 1550 FEG instrument with in-lens detector. Particle size histograms were obtained through image analysis on SEM micrographs using ImageJ [66]. The gray scales in the image files were taken as bases, and cropped images-ideally displaying nothing but particles-were obtained through band-pass filtering to increase sharpness and contrast.

X-ray photoelectron spectroscopy (XPS) data were recorded with a PHI Quantum 2000 Scanning ESCA Microprobe using Al $\mathrm{K}_{\alpha 1}$ radiation and a beam diameter of $200 \mu \mathrm{m}$ at the sample. Survey scans were taken in the $0-1100-\mathrm{eV}$ range employing a pass energy of 29.35 $\mathrm{eV}$ and energy resolution of $0.5 \mathrm{eV}$, whereas high-resolution scans were measured with a pass energy of $23.50 \mathrm{eV}$ and energy resolution of $0.025 \mathrm{eV}$. All spectra were analyzed with Multipak and CasaXPS software [67]. A neutralizer filament was employed in order to compensate for sample charging. The $\mathrm{C} 1 \mathrm{~s}$ peak at $248.8 \mathrm{eV}$, due to adventitious carbon, was used to calibrate the spectra.

Extended x-ray absorption fine structure (EXAFS) measurements were performed in fluorescence mode on beamline I811 at MAXLab in Lund, Sweden $[68,69]$. The beamline produces photons with energies of $2.4-21 \mathrm{keV}$, corresponding to a wavelength interval of 0.06-0.5 nm. $\mathrm{Si}(111)$ and $\mathrm{Si}(311)$ changeable double-crystal mirrors were used as monochromators in order to remove high harmonics. The spot size of the beam on the sample was $0.5 \times 0.5 \mathrm{~mm}^{2}$. Energy calibration was carried out using the $\mathrm{Ni} \mathrm{K}$ edge at $8333 \mathrm{eV}$ (on a Ni metal foil). To eliminate problems related to energy shifts, the x-ray absorption spectrum of the Ni metal was recorded for every measurement with $\mathrm{NiO}$ thin-film samples.

EXAFS data analyses were performed with standard methods [70] as follows: After energy calibration, the recorded absorption spectrum below the pre-edge region was fitted to a straight line, and the background contribution above the post-edge region, $\mu_{0}(E)$, was fitted to a fourth-order polynomial. The fitted polynomials were extrapolated through the full energy region, subtracted from the total absorption spectra, and normalized to obtain the EXAFS function $\chi(E)$ according to

$$
\chi(E)=\frac{\mu(E)-\mu_{0}(E)}{\mu_{0}(E)} .
$$

Normalized spectra were converted to $k$-space by

$$
k=\left[\frac{8 \pi^{2} m\left(E-E_{0}\right)}{h^{2}}\right]^{1 / 2},
$$


where $m$ is electron mass and $h$ is Planck's constant. The EXAFS function was multiplied with $k^{3}$ in order to amplify the signal at large $k$ values, since EXAFS oscillations decrease for increasing energy beyond the edge. Fourier transforms of the $k^{3}$-weighted spectra, denoted $\chi(R)$, were subsequently calculated to obtain distances $R$ between a central $\mathrm{Ni}$ atom and its neighboring atoms.

The EXAFS data were analyzed in order to determine parameters in the EXAFS equation expressed as

$$
\chi_{i}(k)=\sum_{j} \frac{N_{j} S_{0}^{2}(k)}{k R_{j}^{2}}\left|f_{\mathrm{eff}}(k)\right|_{j} \exp \left(-2 k^{2} \sigma_{j}^{2}\right) \exp \left[-\frac{2 R_{j}}{\Lambda(k)}\right] \sin \left[2 k R_{j}+\phi_{i j}(k)\right],
$$

where $N_{j}$ is the number of backscattering atoms in the $j^{\text {th }}$ coordination shell, $R_{j}$ is the distance between a central atom and the backscatterers in the $j^{\text {th }}$ shell for single scattering, $S_{0}^{2}(k)$ is an amplitude reduction factor, $f_{\text {eff }}(k)$ is an effective amplitude function for each scattering path, and $\exp \left(-2 k^{2} \sigma_{j}^{2}\right)$, with $\sigma_{j}^{2}$ being the mean square displacement of an atom, is the DebyeWaller factor (DWF) in the harmonic approximation, which can be used to assess configurational and thermal disorder. Furthermore, $\Lambda(k)$ is the photoelectron mean free path, and $2 k R_{j}+\phi_{i j}(k)$ represents the total phase. All calculations were performed with the ATHENA software within the Demeter software package [71], which uses the ATOMS and FEFF6 programs to perform interatomic bond calculations [72].

\section{Results and discussion}

Data were recorded for samples with three values of the film thickness, specifically 1700 $\mathrm{nm}$ (Sample 1), $600 \mathrm{~nm}$ (Sample 2), and $300 \mathrm{~nm}$ (Sample 3). In order to have a consistent presentation, we report results for Sample 1 below, whereas results for Samples 2 and 3 are given in Supporting Material.

\subsection{Crystal structure by XRD}

Fig. 2 shows $\mathrm{x}$-ray diffractograms for Sample 1 in as-deposited state and after annealing at 400 and $500{ }^{\circ} \mathrm{C}$. The data display peaks that could be indexed according to the International Centre for Diffraction Data (ICCD 04-001-9373) and signaled a face centered cubic NiO structure with a lattice parameter of $0.417 \mathrm{~nm}$. The sharpness of the diffraction features increased upon annealing, and an application of Scherrer's equation [73] to the distinct $<200>$ 
peak yielded that the mean crystallite size increased from 3.7 to $11.4 \mathrm{~nm}$ upon annealing. Similar data for Samples 2 and 3 are reported in Supporting Information (Fig. S1), and extracted crystallite sizes are summarized in Table 1. Clearly crystallite growth was not strongly dependent on film thickness.

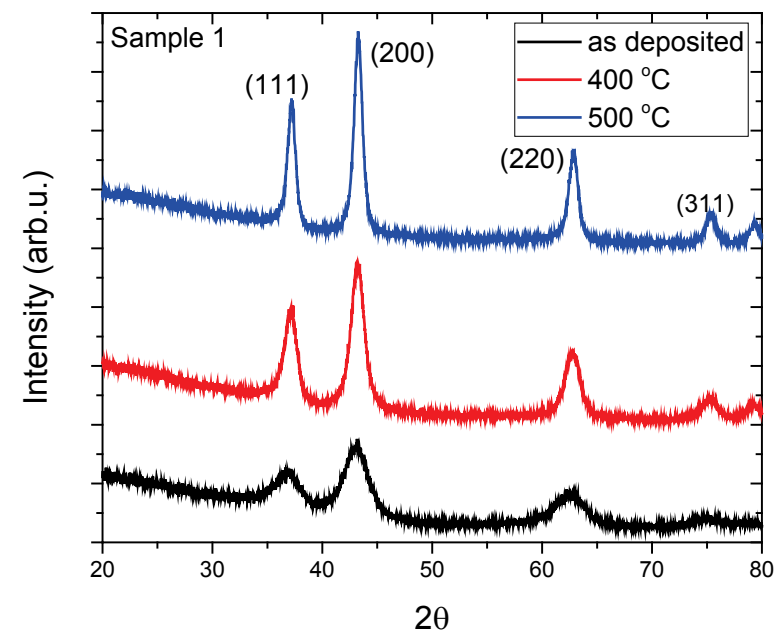

Figure 2. X-ray diffraction data for a 1700 -nm-thick $\mathrm{NiO}$ film (Sample 1) in as-deposited state and after annealing at the shown temperatures. The peaks are assigned to fcc $\mathrm{NiO}$ with the stated Miller indices.

Table 1. Sample data, showing film thickness, annealing temperature, and mean crystallite size from $\mathrm{x}$-ray diffraction.

\begin{tabular}{|c|c|c|c|}
\hline $\begin{array}{c}\text { Sample } \\
\text { number }\end{array}$ & $\begin{array}{c}\text { Film thickness } \\
(\mathrm{nm})\end{array}$ & $\begin{array}{c}\text { Annealing temperature } \\
\left({ }^{\circ} \mathrm{C}\right)\end{array}$ & $\begin{array}{c}\text { Mean crystallite size } \\
(\mathrm{nm})\end{array}$ \\
\hline 1 & 1700 & As-deposited & 3.7 \\
& & 400 & 5.9 \\
& & 500 & 11.4 \\
\hline 2 & 600 & As-deposited & 3.3 \\
& & 400 & 6.2 \\
& & 500 & 9.4 \\
\hline 3 & 300 & As-deposited & 3.1 \\
& & 500 & 8.6 \\
\hline
\end{tabular}

\subsection{Surface features by SEM}

Fig. 3 reports a SEM image of the surface of the 1700-nm-thick NiO film (Sample 1) annealed at $400{ }^{\circ} \mathrm{C}$. Tiny structural features are apparent, whose sizes can be reconciled with 
those of the mean crystallites inferred from XRD. Fig S2 reports complementary data for Sample 1 in as-deposited state and after annealing at $500{ }^{\circ} \mathrm{C}$, and Figs. S3 and S4 give analogous information for Samples 2 and 3, respectively.

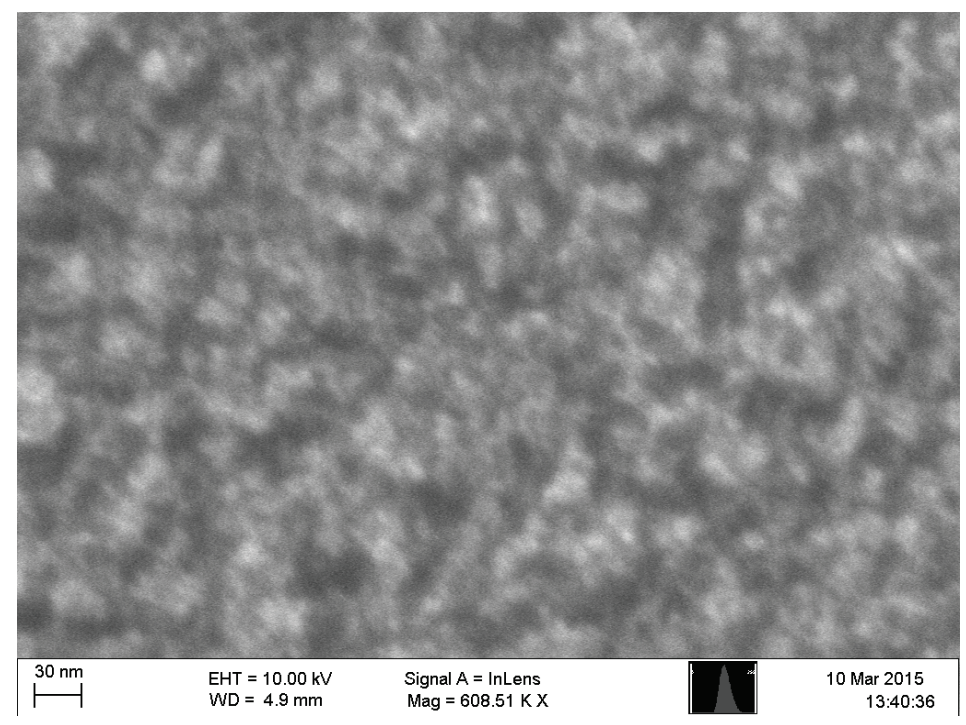

Figure 3. Scanning electron micrograph of the surface a 1700-nm-thick NiO film (Sample 1) annealed at $400{ }^{\circ} \mathrm{C}$.

"Particle" size distributions were derived as outlined above in an attempt to quantify the information in the micrographs, and these distributions were compared with log-normal distributions [74]. Such comparisons are justified since prior analyses on AGD-prepared powder-like deposits demonstrated that log-normality can ensue from processes involving coagulation [50] as well as particles moving by drift and diffusion through a finite growth region $[75,76]$. However, while log-normal particle distributions were demonstrated in some cases, the data (not shown) was in general ambiguous and did not clearly support lognormality, and it therefore remains unclear whether our simplistic approach to SEM imageanalysis was able to provide accurate information about particle distributions.

\subsection{Electronic structure by XPS}

XPS spectra for the NiO thin-film samples were recorded within the spectral regions pertinent to $\mathrm{C} 1 \mathrm{~s}, \mathrm{O} 1 \mathrm{~s}$ and Ni $2 \mathrm{p}$. Data for C 1s were used solely for energy calibration. Spectra in the range of Ni $2 p_{3 / 2}$, shown in Fig. 4 for the 1700-nm-thick NiO film (Sample 1), were dominated by two overlapping peaks centered at 854.6 and $856.1 \mathrm{eV}$, which are due to a 
combination of complex intra-atomic multiplet contributions of $\mathrm{Ni}^{2+}$ and $\mathrm{Ni}^{3+}$ ions [77]. $\mathrm{A}$ shake-up satellite is apparent with an energy separation of $\sim 6 \mathrm{eV}$. The intensity ratio between the low-energy and high-energy peaks is smaller for the as-deposited sample than after its annealing at $500{ }^{\circ} \mathrm{C}$, which is consistent with an increase of crystallinity since the spectrum for the annealed sample is more similar to $\mathrm{NiO}$ [77]. Analogous data for Samples 2 and 3 are given in Fig. S5.

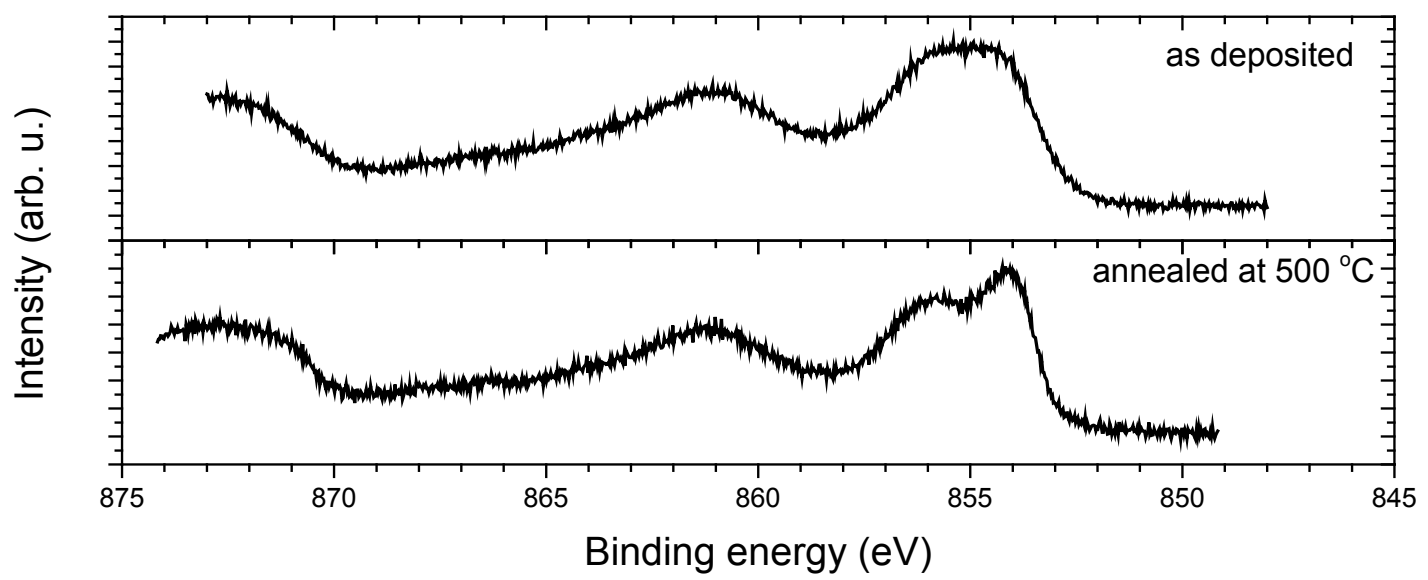

Figure 4. XPS spectra due to Ni $2 \mathrm{p}_{3 / 2}$ for a 1700 -nm-thick NiO film (Sample 1) in as-deposited state and after annealing at the shown temperature. Intensity (arbitrary units) is shown on the ordinate axis.

XPS spectra for O 1s exhibited two major peaks at 529.7 and $531.4 \mathrm{eV}$, as shown in Fig. 5 for the same sample as in Fig. 4. The results agree with literature data [78,79]. The peak at $529.7 \mathrm{eV}$ is due to $\mathrm{O}$ in $\mathrm{NiO}$ [79], whereas the peak at $531.4 \mathrm{eV}$ can be attributed to $\mathrm{O}$ coordinated to $\mathrm{Ni}^{3+}$ and is associated with either a $\mathrm{Ni}_{2} \mathrm{O}_{3}$-type structure or with defects in $\mathrm{NiO}$ [80]. A minor contribution centered at $\sim 533 \mathrm{eV}$ can be related to $\mathrm{O}$ in water. Annealing increased the intensity of the peak at $529.7 \mathrm{eV}$ and significantly decreased the intensity of the peak at $531.4 \mathrm{eV}$, which indicates a diminishing number of defects and/or oxidation of $\mathrm{Ni}_{2} \mathrm{O}_{3}-$ type structures, as expected for crystallite growth. Furthermore, the peak assigned to water shrank upon heat treatment. Sample 2 showed similar results as apparent from Fig. S6.

Electrical resistance data for our $\mathrm{NiO}$ films were reported in a previous article of ours [13] and show a significant increase with annealing temperature. The increase of resistance was in all cases less than a decade, which is in line with the moderate degree of crystalline growth found by XRD and XPS, as reported above. 


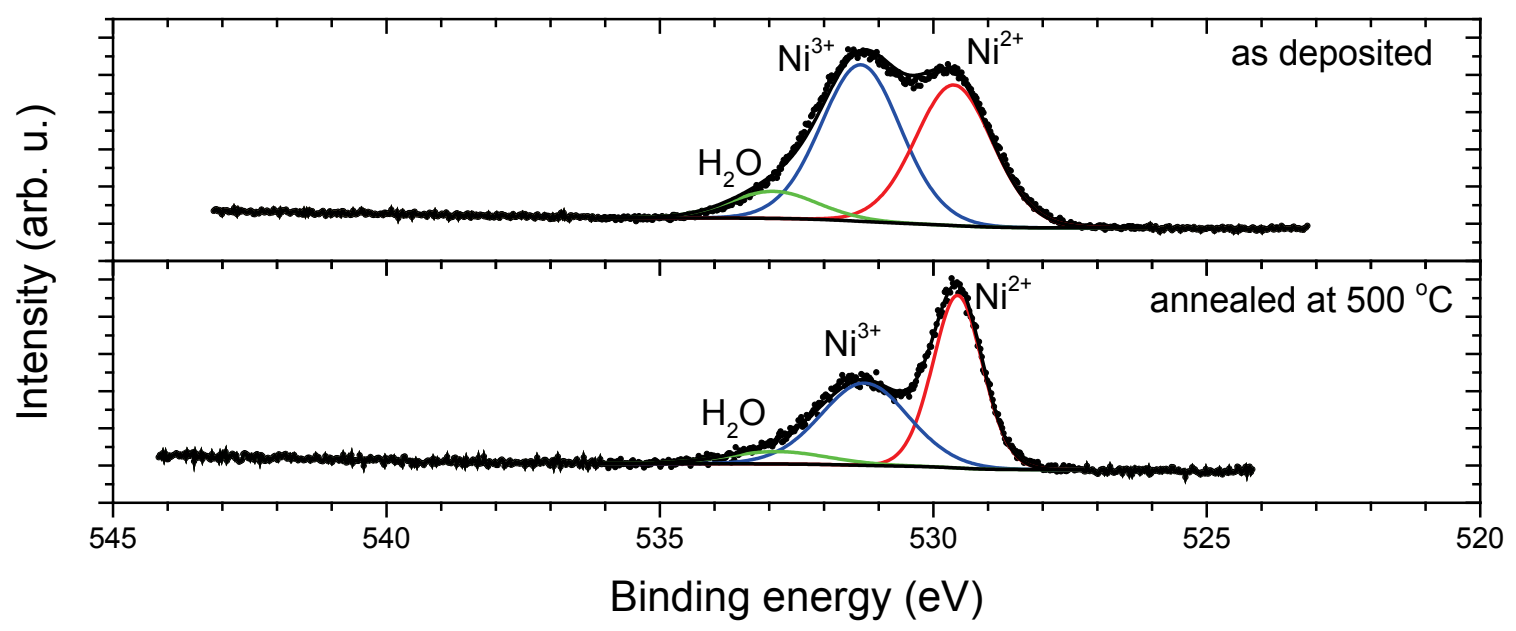

Figure 5. XPS spectra due to O $1 \mathrm{~s}$ for a 1700-nm-thick NiO film (Sample 1) in as-deposited state and after annealing at the shown temperature. Symbols indicate experimental data, which were fitted to Gauss-Lorentzian curves (colored) assigned to the stated species. Intensity (arbitrary units) is shown on the ordinate axis.

\subsection{Interatomic distances and Debye-Waller factors by EXAFS}

EXAFS data were recorded for $\mathrm{NiO}$ thin-film samples annealed at 300,400 and $500{ }^{\circ} \mathrm{C}$, and corresponding spectra of $k^{3} \chi(k)$ were extracted for the Ni K edge at $8333 \mathrm{eV}$, as described above. Fig. 6 reports such results together with the absolute value of their Fourier transforms, $|\chi(R)|$, and demonstrates that calculated results, based on Eq. 3, could be reconciled with the measurements; the data were taken on the 1700-nm-thick NiO film (Sample 1), and analogous results for 600-nm-thick and 300-nm-thick samples are reported in Figs. S7 and S8, respectively. 

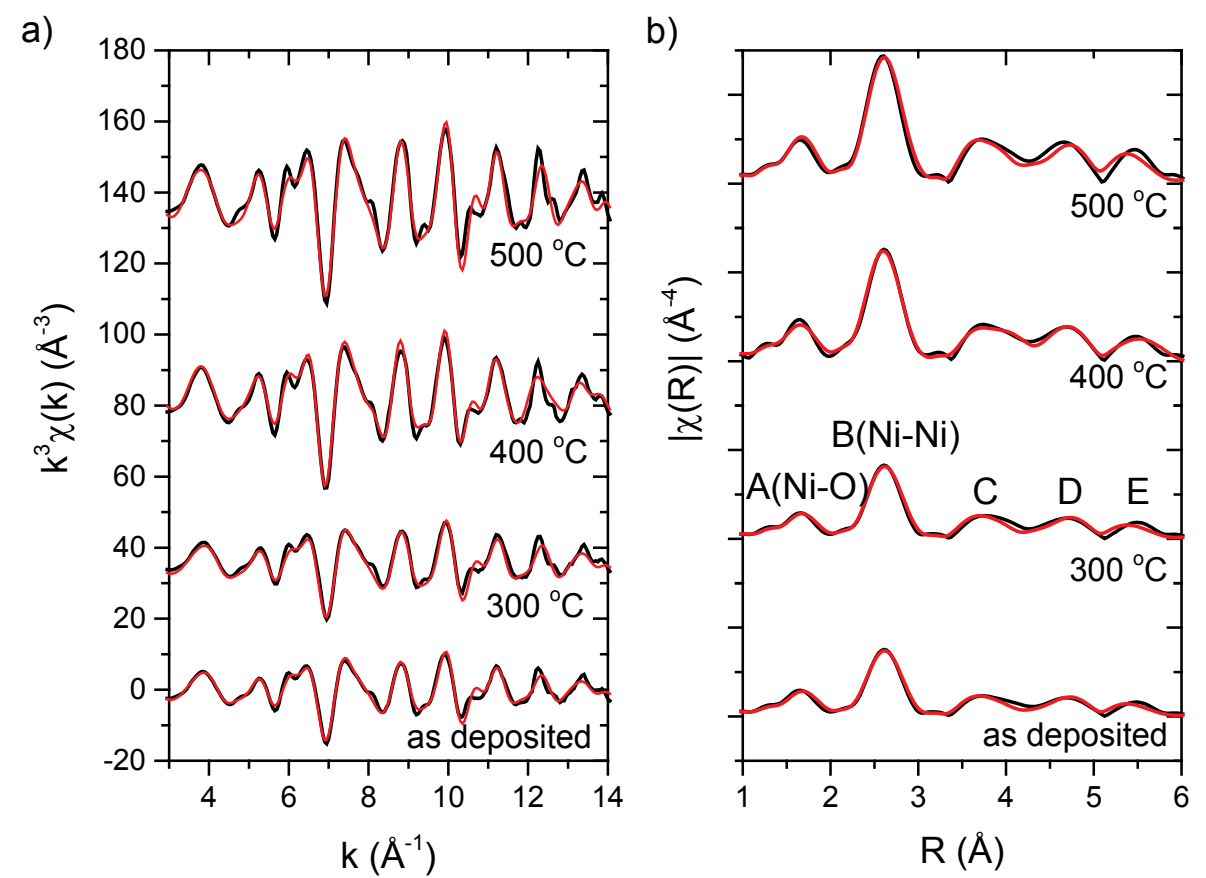

Figure 6. (a) Experimental (black) and simulated (red) data on $k^{3} \chi(k)$ and (b) corresponding Fourier transforms of $k^{3} \chi(k)$ for a 1700-nm-thick NiO film (Sample 1) in as-deposited state and after annealing to the stated temperatures. The peaks for the smallest distances in panel (b), denoted A and B, ensue from the shown nearest-neighbors to core $\mathrm{Ni}$ atoms, whereas the peaks for the larger distances, denoted $\mathrm{C}-\mathrm{E}$, are strongly influenced by multiple scattering. Note that the phase component in the EXAFS equation shifts the peaks from the actual interatomic distances.

Specific parameters for fitting the EXAFS spectra are given in Table 2, which lists values of $N_{j}, R_{j}$ and $\sigma_{j}^{2}$ as well as energy displacements $\Delta E$ relative to the threshold absorption edge energy obtained from the $k$-shift in the fitted data. Data on $N_{j}$ were taken to be the same as in $\mathrm{NiO}$ crystals. The shortest interatomic distances, corresponding to single scattering for $\mathrm{Ni}-\mathrm{O}$ and $\mathrm{Ni}-\mathrm{Ni}$, lie at $2.010 \pm 0.003$ and $2.970 \pm 0.004 \AA$, respectively, and are slightly larger than 2.085 and $2.949 \AA$ pertaining to cubic NiO crystals [81]. The features at larger values of $R_{j}$ in Fig. 6(b) were influenced by multiple scattering [81]. Specifically, the C and D peaks are associated with single scattering from $\mathrm{Ni}-\mathrm{Ni}(2)$ for the second coordination shell with $R_{j}=$ $4.171 \AA$ in the crystalline structure as well with multiple scattering from $\mathrm{Ni}-\mathrm{O}(1)-\mathrm{Ni}(2)$ and $\mathrm{Ni}-\mathrm{O}(1)-\mathrm{Ni}(2)-\mathrm{O}(1)$, which is augmented by a focusing effect for collinear atoms [82]. Similarly, the E peak in Fig. 6(b) is associated with single scattering from $\mathrm{Ni-Ni(4)}$ in the fourth coordination shell with $R_{j}=5.899 \AA$ for $\mathrm{NiO}$ crystals as well as with multiple scattering from $\mathrm{Ni}-\mathrm{Ni}(1)-\mathrm{Ni}(4)$ and $\mathrm{Ni}-\mathrm{Ni}(1)-\mathrm{Ni}(4)-\mathrm{Ni}(1)$ [81]. Analogous sets of parameter values for Samples 2 and 3 in as-deposited state and after annealing at 400 and $500{ }^{\circ} \mathrm{C}$ are given in Tables S1 and S2, respectively. 
Table 2. Curve fitting parameters for Fourier-filtered $k^{3} \chi(k)$ Ni K-edge EXAFS data on a 1700-nmthick $\mathrm{NiO}$ film (Sample 1) in as-deposited state and after annealing at the indicated temperatures. Each atom has been numbered consecutively with regard to its distance from the core $\mathrm{Ni}$ atom. $N_{j}$ is the number of atoms assigned to the $j^{\text {th }}$ coordination shell, $R_{j}$ is the atomic distance from the core Ni atom, $\sigma_{j}^{2}$ represents the mean square displacement of an atom, and $\Delta E$ is the energy shift relative to the threshold absorption edge energy connected with the $k$-shift in the fitted data.

\begin{tabular}{|c|c|c|c|c|c|}
\hline Annealing temperature & Atom & $N_{j}$ & $R_{j}[\AA]$ & $\sigma_{j}^{2}\left[\times 10^{-3}\right]$ & $\Delta E[\mathrm{eV}]$ \\
\hline \multirow[t]{7}{*}{ As-deposited } & $\mathrm{O}(1)$ & 6 & 2.09916 & 5.60 & 1.369 \\
\hline & $\mathrm{Ni}(1)$ & 12 & 2.96862 & 6.45 & -1.822 \\
\hline & $\mathrm{O}(2)$ & 8 & 3.63586 & 7.88 & 6.095 \\
\hline & $\mathrm{Ni}(2)$ & 6 & 4.19832 & 4.81 & -5.246 \\
\hline & $\mathrm{O}(3)$ & 24 & 4.69384 & 17.44 & 2.033 \\
\hline & $\operatorname{Ni}(3)$ & 24 & 5.14186 & 8.54 & -1.047 \\
\hline & $\mathrm{Ni}(4)$ & 12 & 5.93733 & 4.59 & -8.156 \\
\hline \multirow[t]{7}{*}{$300^{\circ} \mathrm{C}$} & $\mathrm{O}(1)$ & 6 & 2.09723 & 5.94 & 1.439 \\
\hline & $\mathrm{Ni}(1)$ & 12 & 2.96588 & 6.01 & -1.183 \\
\hline & $\mathrm{O}(2)$ & 8 & 3.63251 & 7.35 & 6.162 \\
\hline & $\mathrm{Ni}(2)$ & 6 & 4.19445 & 4.15 & -5.192 \\
\hline & $\mathrm{O}(3)$ & 24 & 4.68952 & 15.60 & 2.263 \\
\hline & $\mathrm{Ni}(3)$ & 24 & 5.13712 & 8.15 & -0.767 \\
\hline & $\mathrm{Ni}(4)$ & 12 & 5.93186 & 4.28 & -7.593 \\
\hline \multirow[t]{7}{*}{$400{ }^{\circ} \mathrm{C}$} & $\mathrm{O}(1)$ & 6 & 2.10248 & 5.85 & -0.215 \\
\hline & $\operatorname{Ni}(1)$ & 12 & 2.97331 & 6.26 & -1.452 \\
\hline & $\mathrm{O}(2)$ & 8 & 3.6416 & 6.80 & 5.814 \\
\hline & $\mathrm{Ni}(2)$ & 6 & 4.20495 & 4.28 & -4.592 \\
\hline & $\mathrm{O}(3)$ & 24 & 4.70126 & 13.18 & 4.116 \\
\hline & $\mathrm{Ni}(3)$ & 24 & 5.14998 & 8.06 & -1.383 \\
\hline & $\mathrm{Ni}(4)$ & 12 & 5.94671 & 4.19 & -8.154 \\
\hline \multirow[t]{7}{*}{$500^{\circ} \mathrm{C}$} & $\mathrm{O}(1)$ & 6 & 2.09774 & 4.88 & -0.747 \\
\hline & $\mathrm{Ni}(1)$ & 12 & 2.96661 & 5.81 & -1.772 \\
\hline & $\mathrm{O}(2)$ & 8 & 3.6334 & 6.46 & 5.355 \\
\hline & $\mathrm{Ni}(2)$ & 6 & 4.19549 & 3.89 & -4.793 \\
\hline & $\mathrm{O}(3)$ & 24 & 4.69067 & 10.13 & 3.486 \\
\hline & $\mathrm{Ni}(3)$ & 24 & 5.13839 & 7.51 & -1.837 \\
\hline & $\mathrm{Ni}(4)$ & 12 & 5.93333 & 3.18 & -8.677 \\
\hline
\end{tabular}

Table 2 demonstrates that annealing, in most cases, lowered the values of $\sigma_{j}^{2}$. It is clearly seen that the effect of the heat treatment was much larger for the Debye-Waller factors than for the interatomic separations. Fig. 7 reports quantitative data for the 1700 -nm-thick NiO 
film (Sample 1) and shows that the DWFs are approximately the same for annealing at low annealing temperatures, whereas this parameter is markedly diminished after annealing at 500 ${ }^{\circ} \mathrm{C}$. A lowering of the DWF has been associated with increased crystallinity in earlier work [81]. The near constancy of the $R_{j}$ s indicates that the nano-features prevail after the annealing steps and that the structural data do not approach those pertinent to bulk-like cubic NiO. Analogous data for Samples 2 and 3 are given in Fig. S9 and show, in general, that the DWFs decrease upon annealing. However, the data are not as clear-cut as for Sample 1.

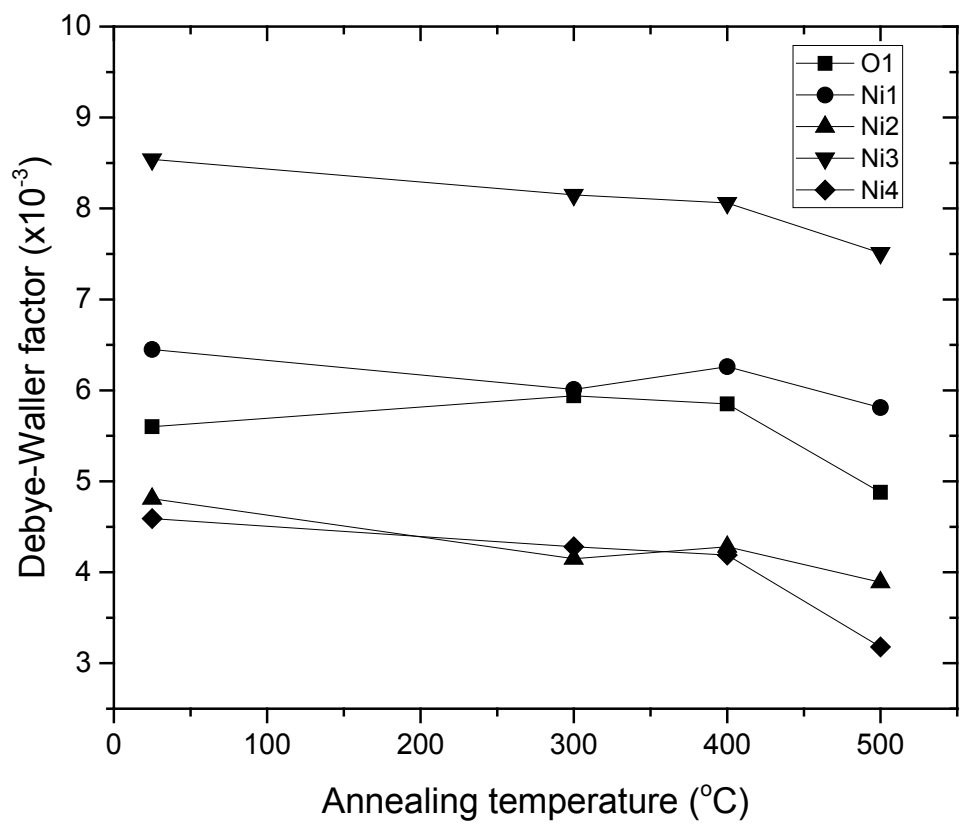

Figure 7. Debye-Waller factors for major coordination shells vs. annealing temperature for a 1700nm-thick NiO film (Sample 1) in as-deposited state and after annealing at the stated temperatures. Data points were connected by straight lines for clarity.

\subsection{Discussion}

It is very difficult to compare gas sensor data from the scientific literature due to the multitude of materials, deposition methods, gas concentrations and presentations of performance data that have been used. Below we give some comments restricted to gas sensors employing $\mathrm{NiO}$, in relation to the present work. Specific gas sensor data for NiO films produced by AGD were given in our previous papers $[3,12,13]$, and we have also discussed the underlying mechanisms for gas sensing [13]. These mechanisms are related to adsorption and desorption of gaseous species on the nickel oxide surfaces with ensuing electron transfer reactions changing the charge carrier concentration in NiO, thereby affecting the measured electrical 
properties [13]. Hence it is commonly believed that a porous material with large surface area will be advantageous for gas sensing and the AGD technique is a versatile method to produce such a nanostructure.

AGD-NiO has been proved to be sensitive for detection of formaldehyde down to concentrations of $0.5 \mathrm{ppm}$ at a sensor temperature of $200{ }^{\circ} \mathrm{C}$ [13] and detection of $\mathrm{H}_{2} \mathrm{~S}$ and $\mathrm{NO}_{2}$ were measured down to $5 \mathrm{ppm}$ at room temperature [3]. The sensitivity to formaldehyde seems to be comparable to the one for nanostructures obtained by chemical synthesis [23] and significantly exceeds the sensitivity of sputter deposited $\mathrm{NiO}$ films [4]. Detection of $\mathrm{H}_{2} \mathrm{~S}$ has been accomplished at lower concentrations, in the ppb-range, by chemically synthesized nanowalls at a sensor temperature of $92{ }^{\circ} \mathrm{C}$ [21]. However, sensitivities at this temperature seem to be comparable to those of AGD-NiO at a concentration of $5 \mathrm{ppm}$.

To sum up, nanostructures with high surface area are suitable for gas sensing, and they can be produced by either AGD or by chemical techniques. Our general reasons for choosing AGD are: firstly, AGD is industrially viable and proven, although data based on samples prepared by AGD are not common in the scientific literature and, secondly, AGD has a principal advantage in that it separates between nanoparticle production and the making of a consolidated material so that inter-particle contacts can be fine-tuned and optimized, at least in principle.

\section{Conclusions}

Thin films of $\mathrm{NiO}$ were prepared by reactive advanced gas deposition. This technique is of particular interest for conductometric gas sensors since it separates the fabrication of individual nanoparticles from the deposition of a consolidated material, and earlier work has demonstrated intriguing gas sensing properties for several gaseous species including formaldehyde [12,13], which is an important pollutant of indoor air $[83,84]$.

The present investigation reported on the characterization of $\mathrm{NiO}$ thin-film samples by several techniques. X-ray diffractometry indicated a face centered cubic $\mathrm{NiO}$ structure with a lattice parameter of $0.417 \mathrm{~nm}$, and scanning electron microscopy provided evidence for a particulate nanostructure. X-ray photoelectron spectroscopy showed the presence of $\mathrm{Ni}^{3+}$ states, which became less prominent after heat treatment. Extended x-ray absorption fine structure analysis elucidated interatomic distances and the influence of annealing on local disorder. Structural stability upon annealing is very important for conductometric gas sensors, 
and our data indicated modest grain growth for a 1700-nm-thick film at annealing temperatures up to $400{ }^{\circ} \mathrm{C}$ whereas more substantial structural changes occurred at $500{ }^{\circ} \mathrm{C}$. These results are in general agreement with those for electrical resistance, as reported in our earlier paper of ours, which specifically described gas sensor performance [13].

\section{Acknowledgments}

Financial support was received from the European Research Council under the European Community's Seventh Framework Program (FP7/2007-2013)/ERC, Grant Agreement No. 267234 (“GRINDOOR”).

\section{References}

[1] I. Hotovy, V. Rehacek, P. Siciliano, S. Capone, L. Spiess, Sensing characteristics of NiO thin films as $\mathrm{NO}_{2}$ gas sensor, Thin Solid Films 418 (2002) 9-15.

[2] C.-Y. Lee, C.-M. Chiang, Y.-H. Wang, R.-H. Ma, A self-heating gas sensor with integrated NiO thin-film for formaldehyde detection, Sensors Actuators B: Chem. 122 (2007) 503-510.

[3] C. Luyo, R. Ionescu, L.F. Reyes, Z. Topalian, W. Estrada, E. Llobet, C.G. Granqvist, P. Heszler, Gas sensing response of $\mathrm{NiO}$ nanoparticle films made by reactive gas deposition, Sensors Actuators B: Chem. 138 (2009) 14-20.

[4] I. Castro-Hurtado, J. Herrán, G.G. Mandayo, E. Castaño, Studies of influence of structural properties and thickness of NiO thin films on formaldehyde detection, Thin Solid Films 520 (2011) 947-952.

[5] B. Liu, H. Yang, H. Zhao, L. An, L. Zhang, R. Shi, L. Wang, L. Bao, Y. Chen, Synthesis and enhanced gas-sensing properties of ultralong $\mathrm{NiO}$ nanowires assembled with $\mathrm{NiO}$ nanocrystals, Sensors Actuators B: Chem. 156 (2011) 251-262.

[6] Y. Du, W. Wang, X. Li, J. Zhao, J. Ma, Y. Liu, G. Lu., Preparation of NiO nanoparticles in microemulsion and its gas sensing performance, Mater. Lett. 68 (2012) 168-170.

[7] J. Mathiyan, D. Sivalingam, J.P. Gopalakrishnan, J.B.B. Rayappan, Spray coated nanostructured nickel oxide thin films for ethanol sensing, J. Appl. Sci. 12 (2012) 1686-1690.

[8] L. Lin, T. Liu, B. Miao, W. Zeng, Synthesis of NiO nanostructures from 1D to 3D and researches of their gas-sensing properties, Mater. Res. Bull. 48 (2013) 449-454.

[9] L. Lin, T. Liu, W. Yu, Z. Gou, W. Zeng, Synthesis of multifarious hierarchical flower-like NiO and their gas-sensing properties, Mater. Res. Bull. 48 (2013) 2730-2736.

[10] S.R. Nalage, M.A. Chougule, S. Sen, V.B. Patil, Novel method for fabrication of NiO sensor for $\mathrm{NO}_{2}$ monitoring, J. Mater. Sci.: Mater. Electron. 24 (2013) 368-375.

[11] A.M. Soleimanpour, Y. Hou, A.H. Jayatissa, Evolution of hydrogen gas sensing properties of solgel derived nickel oxide thin films, Sensors Actuators B: Chem. 182 (2013) 125-133. 
[12] U. Cindemir, Z. Topalian, L. Österlund, C.G. Granqvist, G.A. Niklasson, Porous nickel oxide film sensor for formaldehyde, J. Phys.: Conf. Ser. 559 (2014) 012012/1-012012/5.

[13] U. Cindemir, M. Trawka, J. Smulko, C.G. Granqvist, L. Österlund, G.A. Niklasson, Fluctuationenhanced and conductometric gas sensing with nanocrystalline $\mathrm{NiO}$ thin films: a Comparison, Sensors Actuators B: Chem. 242 (2017) 132-139.

[14] P. Rai, J.-W. Yoon, H.-M. Jeong, S.-J. Hwang, C.-H. Kwak, J.-H. Lee, Design of highly sensitive and selective Au@NiO yolk-shell nanoreactors for gas sensor applications, Nanoscale 6 (2014) 8292 8299.

[15] Y.A.K. Reddy, A.S. Reddy, P.S. Reddy, Enhancement of $\mathrm{NH}_{3}$ gas sensing properties of NiObased thin films deposited by DC reactive magnetron sputtering, Sci. Adv. Mater. 6 (2014) 178-188.

[16] D.S. Dalavi, N.S. Harale, I.S. Mulla, V.K. Rao, V.B. Patil, I.Y. Kim, J.H. Kim, P.S. Patil, Nanoporous network of nickel oxide for ammonia gas detection, Mater. Lett. 146 (2015) 103-107.

[17] C. Dong, X. Xiao, G. Chen, H. Guan, Y. Wang, I. Djerdj, Porous NiO nanosheets self-grown on alumina tube using a novel flash synthesis and their gas sensing properties, RSC Adv. 5 (2015) 48804885.

[18] I. Sta, M. Jlassi, M. Kandyla, M. Hajji, P. Koralli, R. Allagui, M. Kompitsas, H. Ezzaouia, Hydrogen sensing by sol-gel grown NiO and NiO:Li thin films, J. Alloys Cmpds. 626 (2015) 87-92.

[19] Thi Tanh Le Dang, M. Tonezzer, Van Hieu Nguyen, Hydrothermal growth and hydrogen selective sensing of nickel oxide nanowires, J. Nanomater. (2015) 785856/1-785856/8.

[20] J. Wang, P. Yang, X. Wei, Z. Zhou, Preparation of NiO two-dimensional grainy films and their high-performance gas sensors for ammonia detection, Nanoscale Res. Lett. 10 (2015) 119/1-119/6.

[21] T. Yu, X. Cheng, X. Zhang, L. Sui, Y. Xu, S. Gao, H. Zhao, L. Huo, Highly sensitive $\mathrm{H}_{2} \mathrm{~S}$ detection sensors at low temperature based on hierarchically structured $\mathrm{NiO}$ porous nanowall arrays, J. Mater. Chem. A 3 (2015) 11991-11999.

[22] J. Zhang, D. Zeng, Q. Zhu, J. Wu, K. Xu, T. Liao, G. Zhang, C. Xie, Effect of grain-boundaries in $\mathrm{NiO}$ nanosheet layers room-temperature sensing mechanism under $\mathrm{NO}_{2}$, J. Phys. Chem. 119 (2015) 17930-17939.

[23] D. Lahem, F.R. Lontio, A. Delcorte, L. Bilteryst, M. Debliquy, Formaldehyde gas sensor based on nanostructured nickel oxide and the microstructure effects on its response, IOP Conf. Ser.: Mater. Sci. Engr. 108 (2016) 012002/1-012002/6.

[24] C. Feng, X. Kou, X. Liao, Y. Sun, G. Lu, One-dimensional Cr-doped NiO nanostructures serving as a highly sensitive gas sensor for trace xylene detection, RSC Adv. 4 (2017) 41105-41110.

[25] M. Kaur, B.K. Dadhich, R. Singh, K. Ganapathi, T. Bagwaiya, S. Bhattacharya, A.K. Debnath, K.P. Muthe, S.C. Gadkari, RF sputtered $\mathrm{SnO}_{2}: \mathrm{NiO}$ thin films as sub-ppm $\mathrm{H}_{2} \mathrm{~S}$ sensor operable at room temperature, Sensors Actuators B: Chem. 242 (2017) 389-403.

[26] X. Li, D. Li, J. Xu, H. Jin, D. Jin, X. Peng, B. Hong, J. Li, Y. Yang, H. Ge, X. Wang, Mesoporous-structure enhanced gas-sensing properties of nickel oxides nanowires, Mater. Res. Bull. 89 (2017) 280-285.

[27] X.Q. Li, J.Q. Wei, J.C. Xu, H.X. Jin, D.F. Jin, X.L. Peng, B. Hong, J. Li, Y.T. Yang, H.L. Ge, X. Wang, Highly improved sensibility and selectivity ethanol sensor of mesoporous Fe-doped $\mathrm{NiO}$ nanowires, J. Nanopart. Res. 19 (2017) 396/1-396/11. 
[28] X. San, G. Zhao, G. Wang, Y. Shen, D. Meng, Y. Zhang, F. Meng, Assembly of 3D flower-like $\mathrm{NiO}$ hierarchical architectures by $2 \mathrm{D}$ nanosheets: synthesis and their sensing properties to formaldehyde, RSC Adv. 7 (2017) 3540-3549.

[29] S. Wang, D. Huang, S. Xu, W. Jiang, T. Wang, J. Hu, N. Hu, Y. Su, Y. Zhang, Z. Yang, Twodimensional $\mathrm{NiO}$ nanosheets with enhanced room temperature $\mathrm{NO}_{2}$ sensing performance via $\mathrm{Al}$ doping, Phys. Chem. Chem. Phys. 19 (2017) 19043-19049.

[30] W. Estrada, A.M. Andersson, C.G. Granqvist, Electrochromic nickel-oxide-based coatings made by reactive dc magnetron sputtring: preparation and optical properties, J. Appl. Phys. 64 (1988) 36783683.

[31] E. Avendaño, A. Kuzmin, J. Purans, A. Azens, G.A. Niklasson, C.G. Granqvist, Changes in the local structure of nanocrystalline electrochromic films of hydrated nickel vanadium oxide upon ozoneinduced coloration, Phys. Scr. T115 (2005) 464-466.

[32] R.-T. Wen, G.A. Niklasson, C.G. Granqvist, Electrochromic nickel oxide films and their compatibility with potassium hydroxide and lithium perchlorate in propylene carbonate: optical, electrochemical and stress-related properties, Thin Solid Films 565 (2014) 128-135.

[33] R.-T. Wen, C.G. Granqvist, G.A. Niklasson, Anodic electrochromism for energy-efficient windows: cation/anion-based surface processes and effects of crystal facets in nickel oxide thin films, Adv. Funct. Mater. 25 (2015) 3359-3370.

[34] R.-T. Wen, C.G. Granqvist, G.A. Niklasson, Anodic electrochromic nickel oxide thin films: decay of charge density upon extensive electrochemical cycling, ChemElectroChem 3 (2016) 266275.

[35] H.-Y. Qu, D. Primetzhofer, M.A. Arvizu, Z. Qiu, U. Cindemir, C.G. Granqvist, G.A. Niklasson, Electrochemical rejuvenation of anodically coloring electrochromic nickel oxide thin films, ACS Appl. Mater. Interfaces 9 (2017) 42420-42424.

[36] D.-L. Sun, B.-W. Zhao, J.-B. Liu, H. Wang, H. Yan, Application of nickel oxide nanoparticles in electrochromic materials, Ionics 23 (2017) 1509-1515.

[37] K. Fominykh, J.M. Feckl, J. Sicklinger, M. Döbinger, S. Böcklein, J. Ziegler, L. Peter, J. Rathousky, E.-W. Scheidt, T. Bein, D. Fattakhova-Rohlfing, Ultrasmall dispersible crystalline nickel oxide nanoparticles as high-performance catalysts for electrochemical water splitting, Adv. Funct. Mater. 24 (2014) 3123-3129.

[38] M. Gong, W. Zhou, M.-C. Tsai, J. Zhou, M. Guan, M.-C. Lin, B. Zhang, Y. Hu, D.-Y. Wang, J. Yang, S.J. Pennycook, B.-J. Hwang, H. Dai, Nanoscale nickel oxide/nickel heterostructures for active hydrogen evolution electrocatalysis, Nat. Commun. 5 (2014) 5695/1-5695/6.

[39] G. Eranna, B.C. Joshi, D.P. Runthala, R.P. Gupta, Oxide materials for development of integrated gas sensors: a comprehensive review, Crit. Rev. Solid State Mater. Sci. 29 (2010) 111-188.

[40] N. Barsan, D. Koziej, U. Weimar, Metal oxide-based gas sensor research: how to? Sensors Actuators B: Chem. 121 (2007) 18-35.

[41] G. Korotcenkov, The role of morphology and crystallographic structure of metal oxides in response of conductometric-type gas sensors, Mater. Sci. Engr. R 61 (2008) 1-39.

[42] S. Das, V. Jayaraman, $\mathrm{SnO}_{2}$ : a comprehensive review on structures and gas sensors, Progr. Mater. Sci. 66 (2014) 112-255. 
[43] P. Shankar, J.B.B. Rayappan, Gas sensing mechanism of metal oxides: the role of ambient atmosphere, type of semiconductor and gases: a review, Sci. Lett. J. 4 (2015) 126/1-126/18.

[44] J.A. Thornton, High rate thick film growth, Ann. Rev. Mater. Sci. 7 (1977) 239-260.

[45] I. Petrov, P.B. Barna, L. Hultman, J.E. Greene, Microstructural evolution during film growth, J. Vac. Sci. Technol. A 21 (2003) S117-S128.

[46] A. Anders, A structure zone diagram including plasma-based deposition and ion etching, Thin Solid Films 518 (2010) 4087-4090.

[47] A. Barranco, A. Borras, A.R Gonzalez-Elipe, A. Palmero, Perspectives on oblique deposition of thin films: from fundamentals to devices, Progr. Mater. Sci. 76 (2016) 59-153.

[48] A.H. Pfund, The optical properties of metallic and crystalline powders, J. Opt. Soc. Am. 23 (1933) 375-378.

[49] K. Kimoto, Y. Kamiya, M. Nonoyama, R. Uyeda, An electron microscope study on fine metal particles prepared by evaporation in argon gas at low pressure, Jpn. J. Appl. Phys. 2 (1963) 702-713.

[50] C.G. Granqvist, R.A. Buhrman, Ultrafine metal particles, J. Appl. Phys. 47 (1976) 2200-2219.

[51] C.G. Granqvist, O. Hunderi, Optical properties of ultrafine gold particles, Phys. Rev. B 16 (1977) $3513-3534$.

[52] C. Hayashi, R. Uyeda, A. Tasaki, editors, Ultra-Fine Particles: Exploratory Science and Technology, Noyes, Westwood, NJ, USA, 1997.

[53] F. Naruse, S. Kashu, C. Hayashi, Effect of thermophoresis on 10-nm-diameter nanoparticles in gas flow inside a tube, in: C. Granqvist, L. Kish, W. Marlow, eds., Gas Phase Nanoparticle Synthesis, Kluwer, Dordrecht, The Netherlands, 2004, pp. 29-42.

[54] J.L. Solis, S. Saukko, L. Kish, C.G. Granqvist, V. Lantto, Semiconductor gas sensors based on nanostructured tungsten oxide, Thin Solid Films 391 (2001) 255-260.

[55] J. L. Solis, A. Hoel, L.B. Kish, C.G. Granqvist, Gas-sensing properties of nanocrystalline $\mathrm{WO}_{3}$ films made by advanced reactive gas deposition, J. Am. Ceram. Soc. 84 (2001) 1504-1508.

[56] A. Hoel, L.F. Reyes, P. Heszler, V. Lantto, C.G. Granqvist, Nanomaterials for environmental applications: novel $\mathrm{WO}_{3}$-based gas sensors made by advanced gas depositions, Curr. Appl. Phys. 4 (2004) 547-553.

[57] L.F. Reyes, S. Saukko, A. Hoel, V. Lantto, C.G. Granqvist, Structure engineering of $\mathrm{WO}_{3}$ nanoparticles for porous film applications by advanced reactive gas deposition, J. Eur. Ceram. Soc. 24 (2004) 1415-1419.

[58] L.F. Reyes, A. Hoel, S. Saukko, P. Heszler, V. Lantto, C.G. Granqvist, Gas sensor response studies of pure and activated $\mathrm{WO}_{3}$ nanoparticle films made by advanced reactive gas deposition, Sensors Actuators B 117 (2006) 128-134.

[59] R. Ionesco, A. Hoel, C.G. Granqvist, E. Llobet, P. Heszler, Ethanol and $\mathrm{H}_{2} \mathrm{~S}$ gas detection in air and in reducing and oxidizing ambience: application of pattern recognition to analyze the output from temperature-modulated nanoparticulate $\mathrm{WO}_{3}$ gas sensors, Sensors Actuators B 104 (2005) 124-131. 
[60] R. Ionesco, A. Hoel, C.G. Granqvist, E. Llobet, P. Heszler, Low-level detection of ethanol and $\mathrm{H}_{2} \mathrm{~S}$ with temperature-modulated $\mathrm{WO}_{3}$ nanoparticle gas sensors, Sensors Actuators B 104 (2005) 132139.

[61] L.F. Reyes, S. Saukko, A. Hoel, V. Lantto, C.G. Granqvist, J. Lappalainen, Improved gas response at room temperature of activated nanocrystalline $\mathrm{WO}_{3}$ films, Phys. Scr. T114 (2004) 240 243.

[62] A. Hoel, L.F. Reyes, S. Saukko, P. Heszler, V. Lantto, C.G. Granqvist, Gas sensing with films of nanocrystalline $\mathrm{WO}_{3}$ and $\mathrm{Pd}$ made by advanced reactive gas deposition, Sensors Actuators B 105 (2005) 283-289.

[63] Ł. Lentka, M. Kotarski, J. Smulko, U. Cindemir, Z. Topalian, C.G. Granqvist, R. Calavia, R. Ionescu, Fluctuation-enhanced sensing with organically functionalized gold nanoparticle gas sensors targeting biomedical applications, Talanta 160 (2016) 9-14.

[64] R. Ionescu, U. Cindemir, T.G. Welearygay, R. Calavia, Z. Haddi, Z. Topalian, C.G. Granqvist, E. Llobet, Fabrication of ultra-pure gold nanoparticles capped with dodecanethiol for Schottky-diode chemical gas sensing devices, Sensors Actuators B: Chem. 239 (2017) 455-461.

[65] S.L. Dudarev, G.A. Botton, S.Y. Savrasov, C.J. Humphreys, A. P. Sutton, Electron-energy-loss spectra and the structural stability of nickel oxide: an LSDA + U study, Phys. Rev. B 57 (1998) 15051509.

[66] C.A. Schneider, W.S. Rasband, K.W. Eliceiri, NIH Image to ImageJ: 25 years of image analysis, Nat. Meth. 9 (2012) 671-675.

[67] www.casaxps.com

[68] T.M. Grehk, P.O. Nilsson, The design of the material science beamline, I811, at MAX-II, Nucl. Instrum. Meth. Phys. Res. A 467-468 (2001) 635-638.

[69] S. Carlson, M. Clausén, L. Gridneva, B. Sommarin, C. Svensson, XAFS experiments at beamline I811, MAX-lab synchrotron source, Sweden, J. Synchrotron Radiat. 13 (2006) 359-64.

[70] G. Bunker, Introduction to XAFS: A Practical Guide to X-ray Absorption Fine Structure Spectroscopy, Cambridge University Press, Cambridge, UK, 2010.

[71] B. Ravel, M. Newville, ATHENA, ARTEMIS, HEPHAESTUS: data analysis for X-ray absorption spectroscopy using IFEFFIT, J. Synchrotron Radiat. 12 (2005) 537-541.

[72] B. Ravel, ATOMS : crystallography for the X-ray absorption spectroscopist, J. Synchrotron Radiat. 8 (2001) 314-316.

[73] B.D. Cullity, S.R. Stock, Elements of X-ray Diffraction, $3^{\text {rd }}$ ed., Pearson, Upper Saddle River, NJ, USA, 2001.

[74] J. Aitchison, J.A.C. Brown, The Lognormal Distribution, Cambridge University Press, Cambridge, UK, 1957.

[75] J. Söderlund, L.B. Kiss, G.A. Niklasson, C.G. Granqvist, Lognormal size distributions in particle growth processes without coagulation, Phys. Rev. Lett. 80 (1998) 2386-2388.

[76] L.B. Kiss, J. Söderlund, G.A. Niklasson, C.G. Granqvist, New approach to the origin of lognormal size distributions of nanoparticles, Nanotechnology 10 (1999) 25-28. 
[77] A.P. Grosvenor, M.C. Biesinger, R.St.C. Smart, N.S. McIntyre, New interpretations of XPS spectra of nickel metal and oxides, Surf. Sci. 600 (2006) 1771-1779.

[78] K.S. Kim, N. Winograd, X-ray photoelectron spectroscopic studies of nickel-oxygen surfaces using oxygen and argon ion-bombardment, Surf. Sci. 43 (1974) $62-643$.

[79] A.N. Mansour, Characterization of NiO by XPS, Surf. Sci. Spectra 3 (1996) 231-238.

[80] L.M. Moroney, R.St.C. Smart, M.W. Roberts, Studies of the thermal decomposition of $\beta \mathrm{NiO}(\mathrm{OH})$ and nickel peroxide by x-ray photoelectron spectroscopy, J. Chem. Soc., Faraday Trans. 1, 79 (1983) $1769-1778$.

[81] K.-W. Nam, W.-S. Yoon, K.-B. Kim, X-ray absorption spectroscopy studies of nickel oxide thin film electrodes for supercapacitors, Electrochim. Acta. 47 (2002) 3201-3209.

[82] B.-K. Teo, Novel method for angle determinations by EXAFS via a new multiple-scattering formalism, J. Am. Chem. Soc. 103 (1981) 3990-4001.

[83] D. Norbäck, E. Björnsson, C. Janson, J. Widerström, G. Boman, Asthmatic symptoms and volatile organic compounds, formaldehyde, and carbon dioxide in dwellings, Occup. Environm. Med. 52 (1995) 388-395.

[84] J.-Y- An, S. Kim, H.-J. Kim, J. Seo, Emission behavior of formaldehyde and TVOC from engineered flooring in under heating and air circulation systems, Building Environm. 45 (2010) 18261833. 


\title{
Supporting Information
}

\section{Characterization of Nanocrystalline-Nanoporous Nickel Oxide Thin Films Prepared by Reactive Advanced Gas Deposition}

\author{
U. Cindemir, Z. Topalian, C. G. Granqvist, L. Österlund and G. A. Niklasson* \\ Department of Engineering Sciences, The Ångström Laboratory, Uppsala University, \\ P.O. Box 534, SE-751 21 Uppsala, Sweden
}

* Corresponding author. E-mail: gunnar.niklasson@angstrom.uu.se 

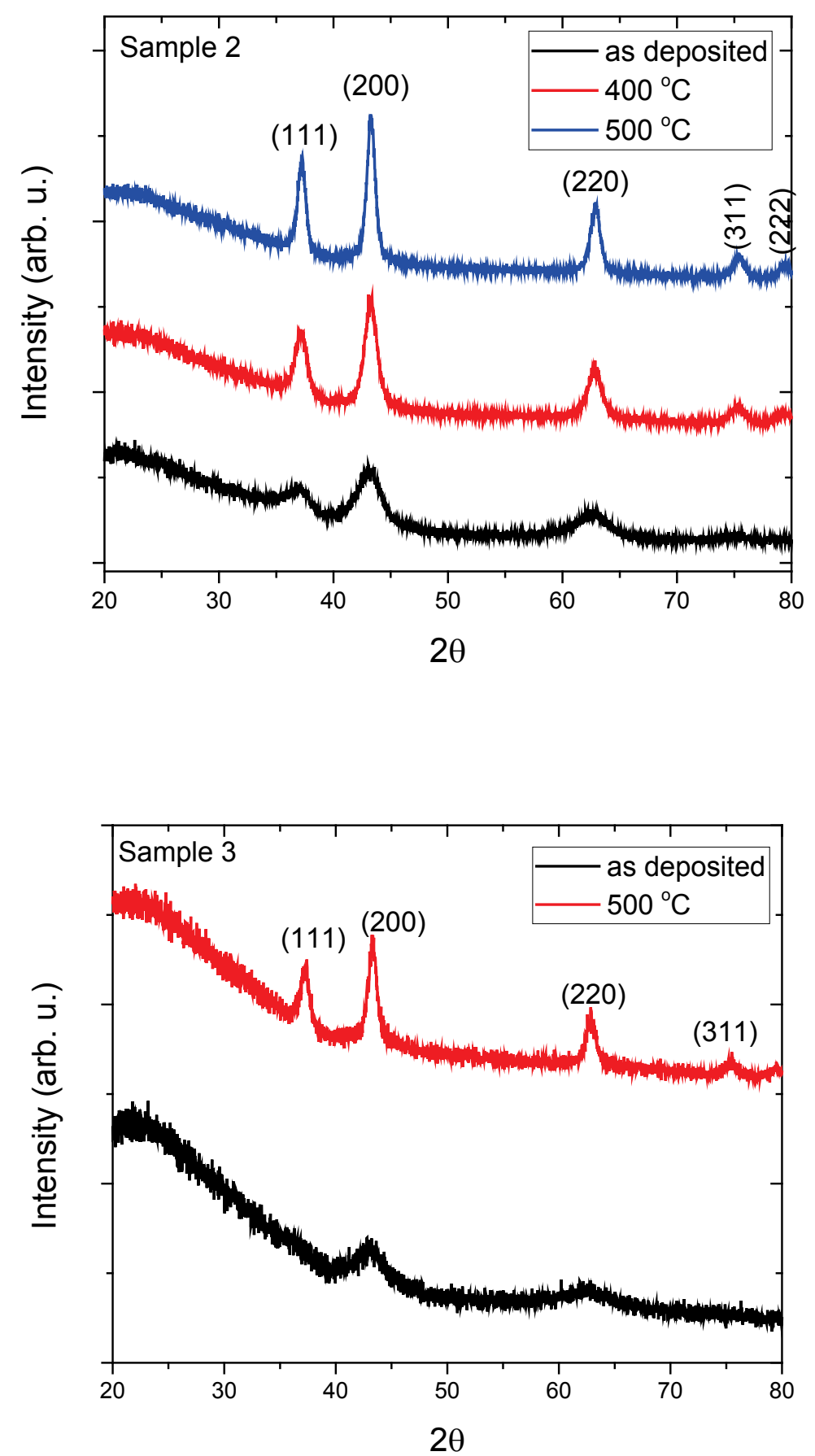

Figure S1. X-ray diffraction data for 600-nm-thick (Sample 2, upper panel) and 300-nm-thick (Sample 3, lower panel) NiO films in as-deposited state and after annealing at the shown temperatures. The peaks are assigned to fcc $\mathrm{NiO}$ with the stated Miller indices. 

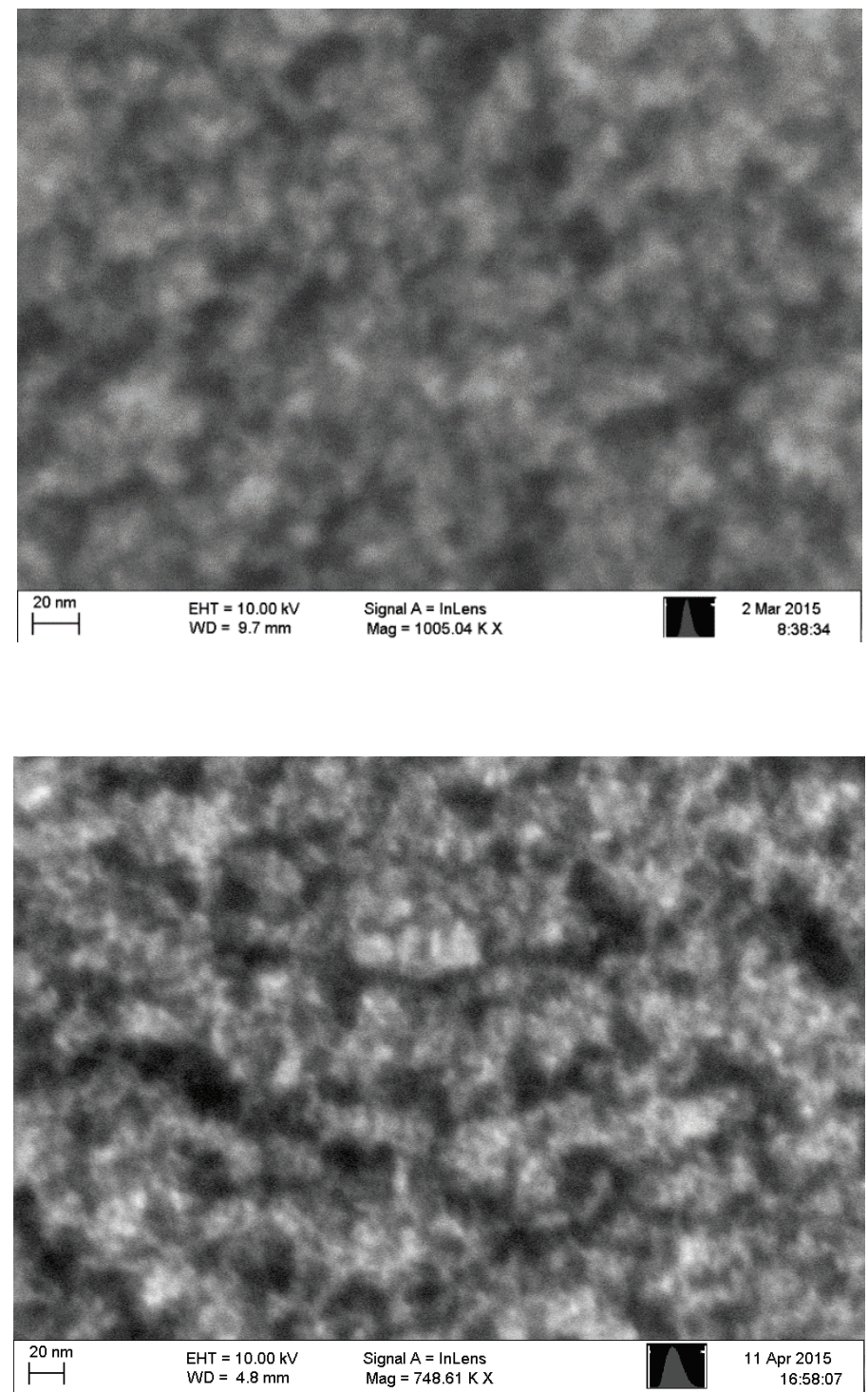

Figure S2. Scanning electron micrographs of the surface a 1700-nm-thick NiO film (Sample 1) in asdeposited state (upper panel) and after annealing at $500{ }^{\circ} \mathrm{C}$ (lower panel). 

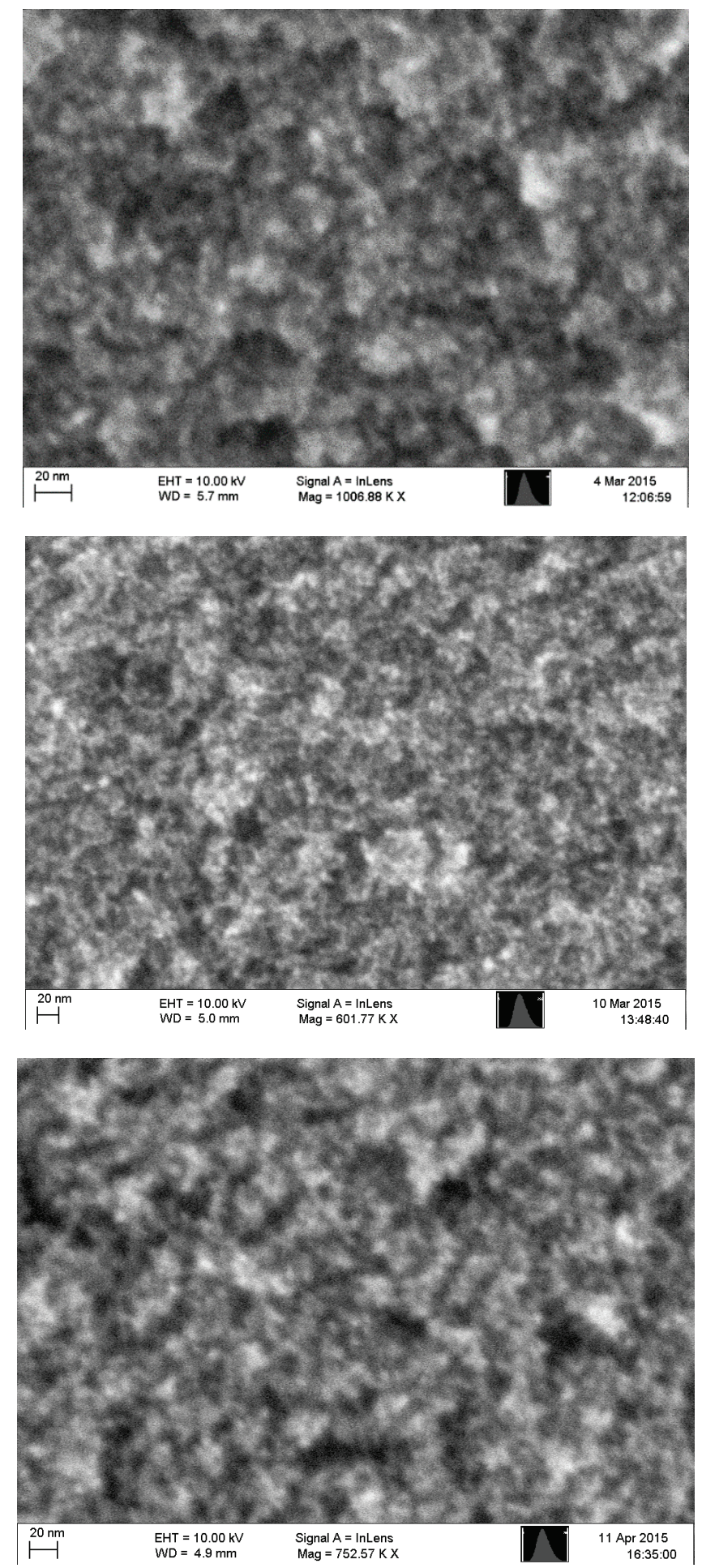

Figure S3. Scanning electron micrographs of the surface a 600-nm-thick NiO film (Sample 2) in asdeposited state (upper panel) and after annealing at $400{ }^{\circ} \mathrm{C}$ (middle panel) and $500{ }^{\circ} \mathrm{C}$ (lower panel). 

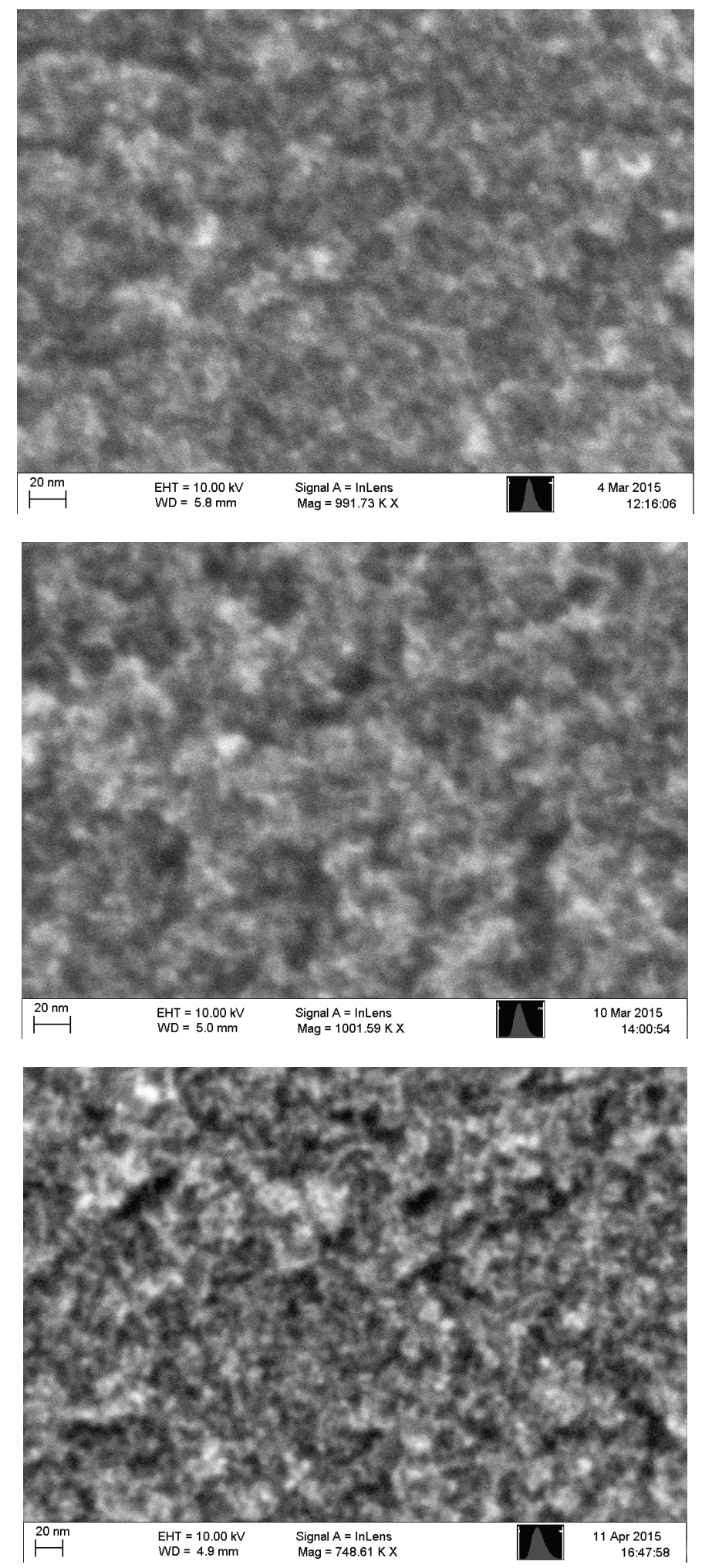

Figure S4. Scanning electron micrograph of the surface a 300-nm-thick NiO film (Sample 3) in asdeposited state (upper panel) and after annealing at $400{ }^{\circ} \mathrm{C}$ (middle panel) and $500{ }^{\circ} \mathrm{C}$ (lower panel). 

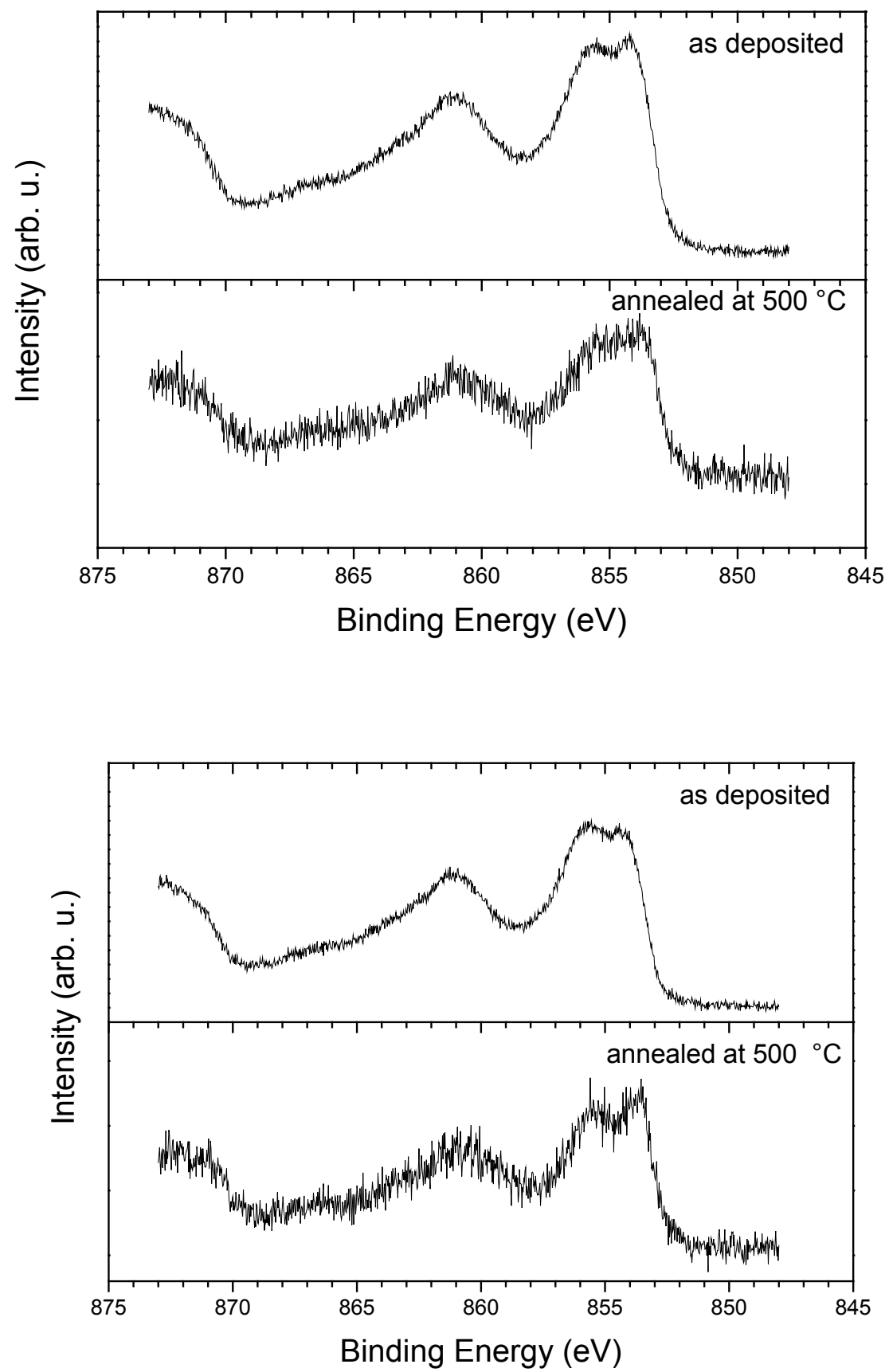

Figure S5. XPS spectra due to Ni $2 p_{3 / 2}$ for 600-nm-thick (Sample 2, upper panel) and 300-nm-thick $\mathrm{NiO}$ films (Sample 3, lower panel) in as-deposited state and after annealing at the shown temperature. Intensity (arbitrary units) is shown on the ordinate axis. 


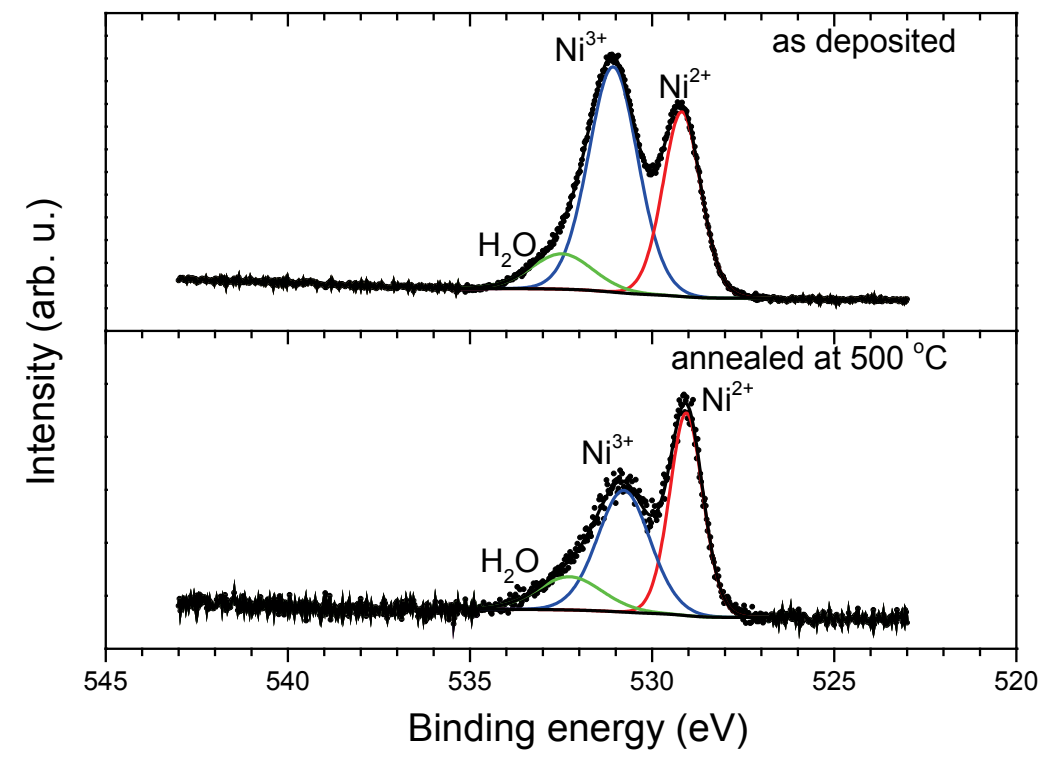

Figure S6. XPS spectra due to O 1s for a 600-nm-thick NiO film (Sample 2) in as-deposited state and after annealing at the shown temperature. Symbols indicate experimental data, which were fitted to Gauss-Lorentzian curves (colored). Intensity (arbitrary units) is shown on the ordinate axis. 

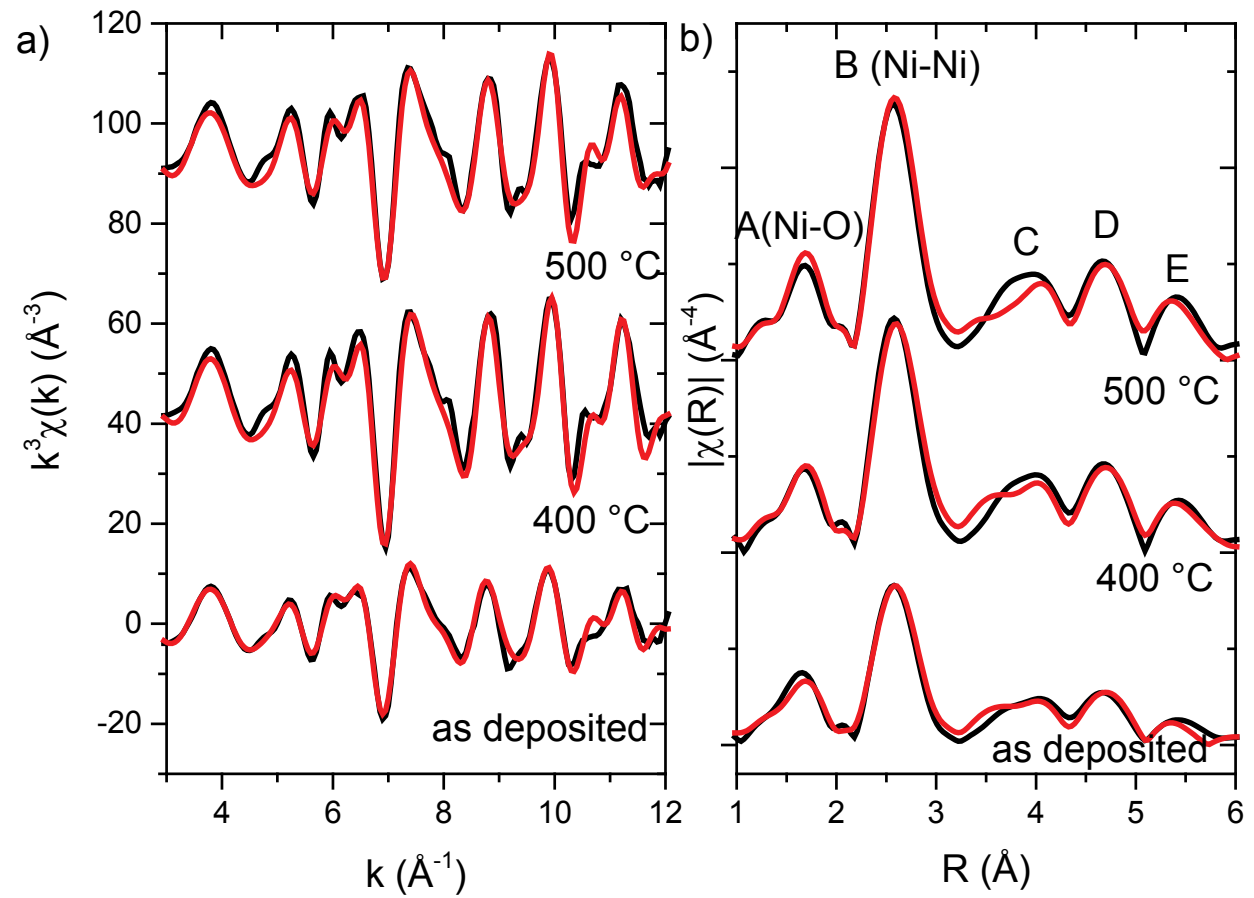

Figure S7. (a) Experimental (black) and simulated (red) data on $k^{3} \chi(k)$ and (b) corresponding Fourier transforms of $k^{3} \chi(k)$ for a 600 -nm-thick NiO film (Sample 2) in as-deposited state and after annealing to the stated temperatures. The peaks for the smallest distances in panel (b), denoted A and B, ensue from the shown nearest-neighbors to core $\mathrm{Ni}$ atoms, whereas the peaks for the larger distances, denoted $\mathrm{C}-\mathrm{E}$, are strongly influenced by multiple scattering. Note that the phase component in the EXAFS equation shifts the peaks from the actual interatomic distances. 
sample 3
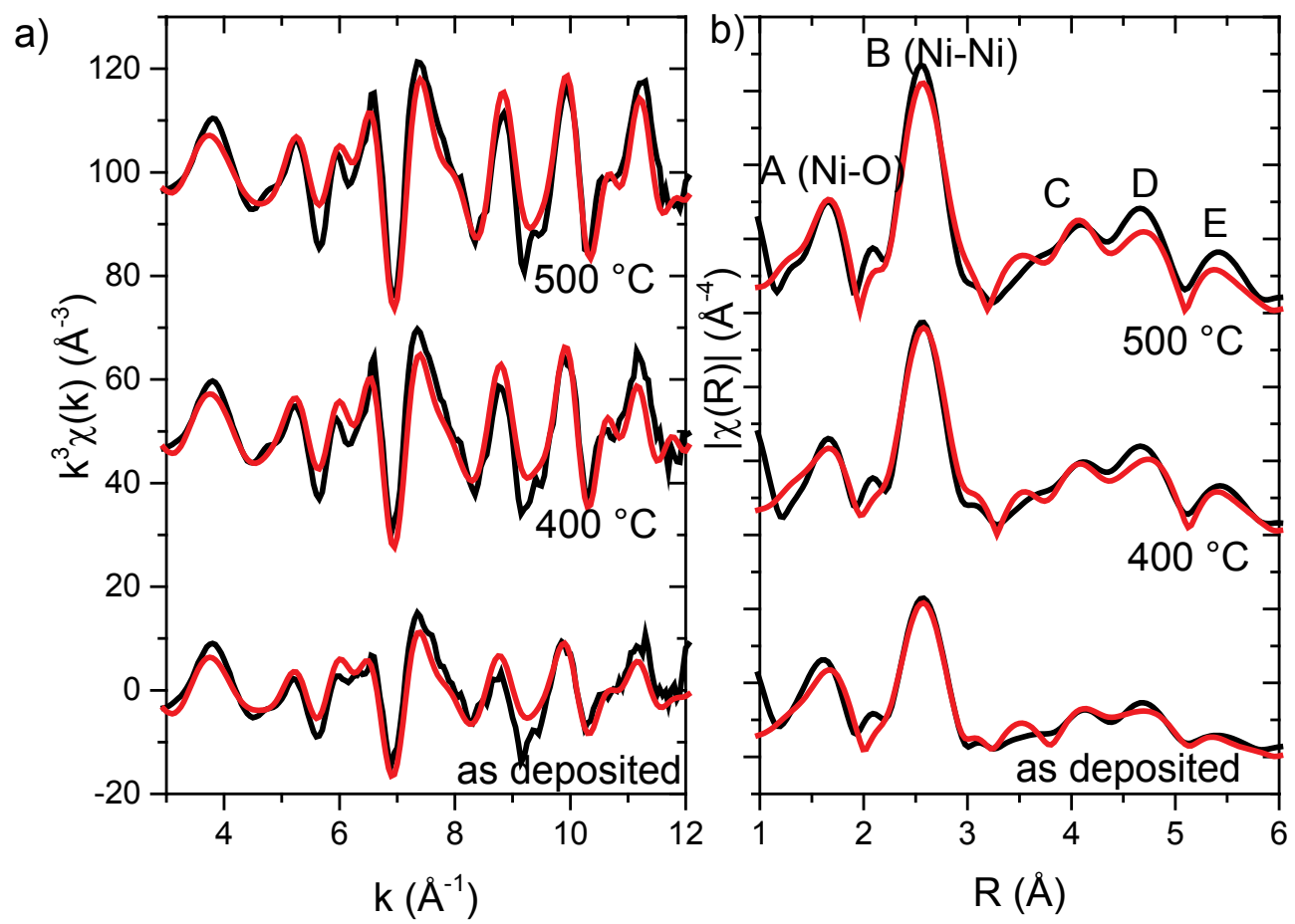

Figure S8. (a) Experimental (black) and simulated (red) data on $k^{3} \chi(k)$ and (b) corresponding Fourier transforms of $k^{3} \chi(k)$ for a 300-nm-thick NiO film (Sample 3) in as-deposited state and after annealing to the stated temperatures. The peaks for the smallest distances in panel (b), denoted A and B, ensue from the shown nearest-neighbors to core $\mathrm{Ni}$ atoms, whereas the peaks for the larger distances, denoted $\mathrm{C}-\mathrm{E}$, are strongly influenced by multiple scattering. Note that the phase component in the EXAFS equation shifts the peaks from the actual interatomic distances. 

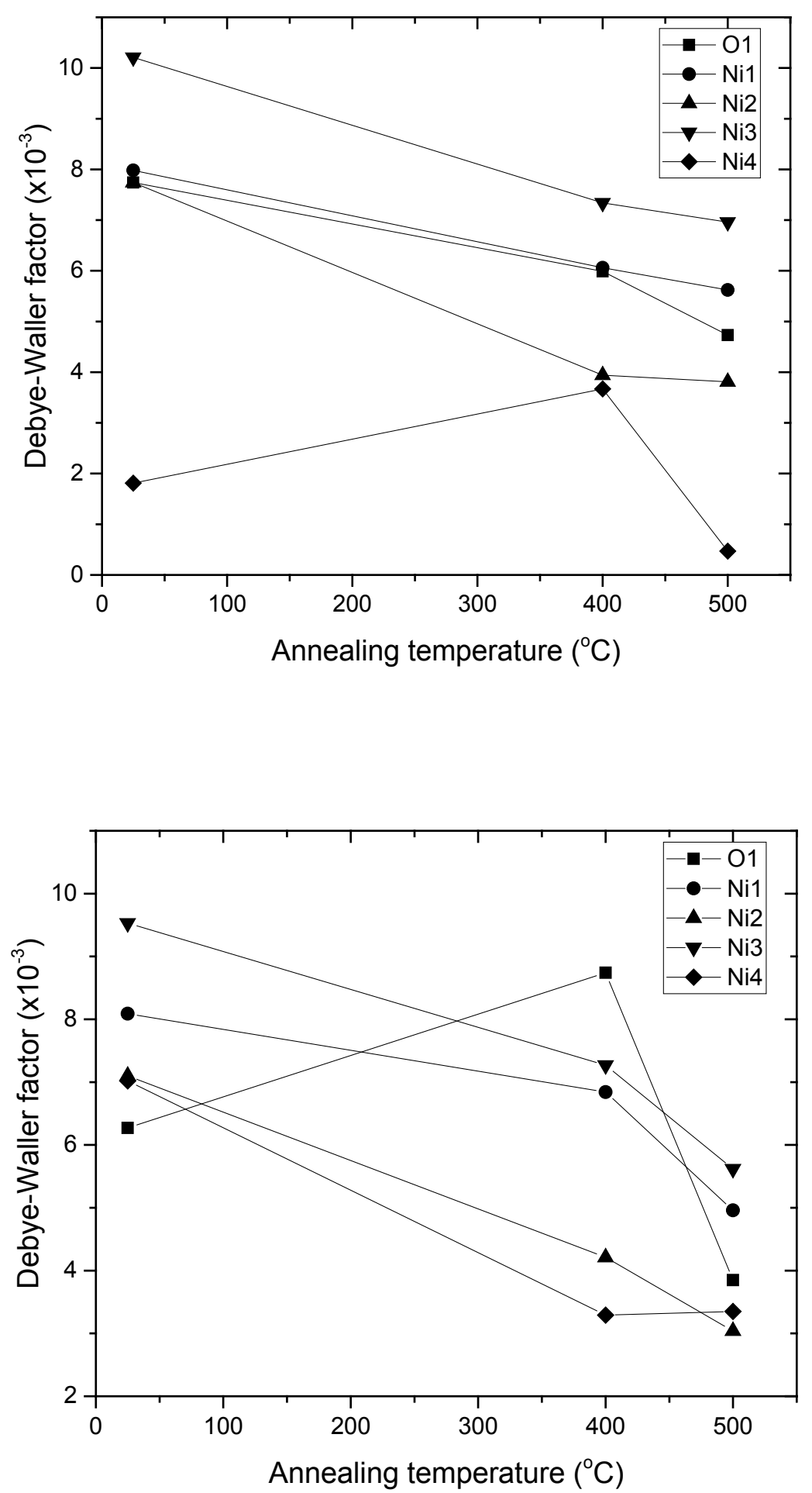

Figure S9. Debye-Waller factors for major coordination shells vs. annealing temperature for 600-nmthick (Sample 2, upper panel) and 300-nm-thick (lower panel, Sample 3) NiO films in as-deposited state and after annealing at the stated temperatures. Data points were connected by straight lines for clarity. 
Table S1. Curve fitting parameters for Fourier-filtered $k^{3} \chi(k)$ Ni K-edge EXAFS data on a 600-nmthick NiO film (Sample 2) in as-deposited state and after annealing at the indicated temperatures. Each atom has been numbered consecutively with regard to its distance from the core $\mathrm{Ni}$ atom. $N_{j}$ is the number of atoms assigned to the $j^{\text {th }}$ coordination shell, $R_{j}$ is the atomic distance from the core Ni atom, $\sigma_{j}^{2}$ represents the mean square displacement of an atom, and $\Delta E$ is the energy shift relative to the threshold absorption edge energy connected with the k-shift in the fitted data.

\begin{tabular}{|c|c|c|c|c|c|}
\hline Annealing temperature & Atom & $N_{j}$ & $R_{j}[\AA]$ & $\sigma_{j}^{2}\left[\times 10^{-3}\right]$ & $\Delta E[\mathrm{eV}]$ \\
\hline \multirow[t]{7}{*}{ As-deposited } & $\mathrm{O}(1)$ & 6 & 2.10479 & 7.74 & 0.284 \\
\hline & $\mathrm{Ni}(1)$ & 12 & 2.97659 & 7.98 & -2.35 \\
\hline & $\mathrm{O}(2)$ & 8 & 3.64562 & 8.21 & 5.989 \\
\hline & $\mathrm{Ni}(2)$ & 6 & 4.20959 & 7.74 & 0.284 \\
\hline & $\mathrm{O}(3)$ & 24 & 4.70644 & 17.36 & 4.053 \\
\hline & $\mathrm{Ni}(3)$ & 24 & 5.15566 & 10.21 & -1.686 \\
\hline & $\mathrm{Ni}(4)$ & 12 & 5.95327 & 1.81 & -4.686 \\
\hline \multirow[t]{7}{*}{$400^{\circ} \mathrm{C}$} & $\mathrm{O}(1)$ & 6 & 2.10345 & 5.99 & -0.371 \\
\hline & $\mathrm{Ni}(1)$ & 12 & 2.97468 & 6.06 & -1.097 \\
\hline & $\mathrm{O}(2)$ & 8 & 3.64329 & 5.88 & 6.08 \\
\hline & $\mathrm{Ni}(2)$ & 6 & 4.2069 & 3.94 & -4.108 \\
\hline & $\mathrm{O}(3)$ & 24 & 4.70343 & 8.69 & 4.907 \\
\hline & $\mathrm{Ni}(3)$ & 24 & 5.15236 & 7.34 & -1.194 \\
\hline & $\mathrm{Ni}(4)$ & 12 & 5.94946 & 3.67 & -7.234 \\
\hline \multirow[t]{7}{*}{$500^{\circ} \mathrm{C}$} & $\mathrm{O}(1)$ & 6 & 2.09702 & 4.73 & -0.785 \\
\hline & $\mathrm{Ni}(1)$ & 12 & 2.9656 & 5.62 & -1.853 \\
\hline & $\mathrm{O}(2)$ & 8 & 3.63216 & 6.19 & 6.177 \\
\hline & $\mathrm{Ni}(2)$ & 6 & 4.19404 & 3.81 & -4.065 \\
\hline & $\mathrm{O}(3)$ & 24 & 4.68906 & 8.95 & 4.338 \\
\hline & Ni(3) & 24 & 5.13662 & 6.96 & -2.038 \\
\hline & $\mathrm{Ni}(4)$ & 12 & 5.93129 & 0.47 & -5.364 \\
\hline
\end{tabular}


Table S2. Curve fitting parameters for Fourier-filtered $k^{3} \chi(k)$ Ni K-edge EXAFS data on a 300-nmthick NiO film (Sample 3) in as-deposited state and after annealing at the indicated temperatures. Each atom has been numbered consecutively with regard to its distance from the core $\mathrm{Ni}$ atom. $N_{j}$ is the number of atoms assigned to the $j^{\text {th }}$ coordination shell, $R_{j}$ is the atomic distance from the core Ni atom, $\sigma_{j}^{2}$ represents the mean square displacement of an atom, and $\Delta E$ is the energy shift relative to the threshold absorption edge energy connected with the $k$-shift in the fitted data.

\begin{tabular}{|c|c|c|c|c|c|}
\hline Annealing temperature & Atom & $N_{j}$ & $R_{j}[\AA]$ & $\sigma_{j}^{2}\left[\times 10^{-3}\right]$ & $\Delta E[\mathrm{eV}]$ \\
\hline \multirow[t]{7}{*}{ As-deposited } & $\mathrm{O}(1)$ & 6 & 2.10746 & 6.27 & 1.430 \\
\hline & $\mathrm{Ni}(1)$ & 12 & 2.98035 & 8.09 & -2.148 \\
\hline & $\mathrm{O}(2)$ & 8 & 3.65023 & 10.46 & 4.543 \\
\hline & $\operatorname{Ni}(2)$ & 6 & 4.21491 & 7.1 & -4.175 \\
\hline & $\mathrm{O}(3)$ & 24 & 4.71239 & 8.43 & 5.395 \\
\hline & $\mathrm{Ni}(3)$ & 24 & 5.16218 & 9.53 & -1.243 \\
\hline & $\mathrm{Ni}(4)$ & 12 & 5.9608 & 7.02 & -7.108 \\
\hline \multirow[t]{7}{*}{$400^{\circ} \mathrm{C}$} & $\mathrm{O}(1)$ & 6 & 2.11062 & 8.74 & -0.957 \\
\hline & $\mathrm{Ni}(1)$ & 12 & 2.98483 & 6.84 & 0.452 \\
\hline & $\mathrm{O}(2)$ & 8 & 3.65572 & 4.85 & 4.918 \\
\hline & $\mathrm{Ni}(2)$ & 6 & 4.22125 & 4.21 & -3.09 \\
\hline & $\mathrm{O}(3)$ & 24 & 4.71948 & 5.38 & 5.604 \\
\hline & $\mathrm{Ni}(3)$ & 24 & 5.16994 & 7.27 & 0.165 \\
\hline & $\mathrm{Ni}(4)$ & 12 & 5.96976 & 3.29 & -5.256 \\
\hline \multirow[t]{7}{*}{$500^{\circ} \mathrm{C}$} & $\mathrm{O}(1)$ & 6 & 2.09815 & 3.85 & -1.517 \\
\hline & $\mathrm{Ni}(1)$ & 12 & 2.96719 & 4.96 & -0.731 \\
\hline & $\mathrm{O}(2)$ & 8 & 3.63412 & 11.16 & 4.204 \\
\hline & $\mathrm{Ni}(2)$ & 6 & 4.19631 & 3.04 & -2.553 \\
\hline & $\mathrm{O}(3)$ & 24 & 4.69159 & 2.01 & 4.652 \\
\hline & $\mathrm{Ni}(3)$ & 24 & 5.13939 & 5.62 & -1.848 \\
\hline & $\mathrm{Ni}(4)$ & 12 & 5.93449 & 3.35 & -5.946 \\
\hline
\end{tabular}

